\title{
Specific Acetylation of p53 by HDAC Inhibition Prevents DNA Damage-Induced Apoptosis in Neurons
}

\author{
Camille Brochier, ${ }^{1,2}$ Gretel Dennis, ${ }^{1}$ Mark A. Rivieccio, ${ }^{1,2}$ Kathryn McLaughlin, ${ }^{1}$ Giovanni Coppola, ${ }^{3}$ Rajiv R. Ratan, ${ }^{1,2}$ \\ and Brett Langley ${ }^{1,2}$ \\ ${ }^{1}$ The Burke Medical Research Institute, White Plains, New York 10605, ${ }^{2}$ Department of Neurology and Neuroscience, Weill Medical College of Cornell \\ University, New York, New York 10065, and ' ${ }^{2}$ Department of Neurology, David Geffen School of Medicine, University of California Los Angeles, Los Angeles, \\ California 90095
}

Histone deacetylase (HDAC) inhibitors have been used to promote neuronal survival and ameliorate neurological dysfunction in a host of neurodegenerative disease models. The precise molecular mechanisms whereby HDAC inhibitors prevent neuronal death are currently the focus of intensive research. Here we demonstrate that HDAC inhibition prevents DNA damage-induced neurodegeneration by modifying the acetylation pattern of the tumor suppressor $\mathrm{p} 53$, which decreases its DNA-binding and transcriptional activation of target genes. Specifically, we identify that acetylation at K382 and K381 prevents p53 from associating with the pro-apoptotic PUMA gene promoter, activating transcription, and inducing apoptosis in mouse primary cortical neurons. Paradoxically, acetylation of p53 at the same lysines in various cancer cell lines leads to the induction of PUMA expression and death. Together, our data provide a molecular understanding of the specific outcomes of HDAC inhibition and suggest that strategies aimed at enhancing p53 acetylation at K381 and K382 might be therapeutically viable for capturing the beneficial effects in the CNS, without compromising tumor suppression.

\section{Introduction}

Histone deacetylases (HDACs) and histone acetyltransferases (HATs) play important roles in the control of protein acetylation homeostasis and the regulation of basic cellular activities such as gene expression. Disruption of the balance between HAT and HDAC activities leads to a disequilibrium in acetylation and transcriptional dysregulation, two established features of neurodegeneration (Rouaux et al., 2004). Treatment with various HDAC inhibitors (HDACis) can adjust these deficiencies and has emerged as an attractive therapeutic approach for neurodegeneration in the last decade (Kazantsev and Thompson, 2008; Langley et al., 2009). In addition to neuroprotection, there is growing evidence that HDACis can also enhance learning and memory (Fischer et al., 2007) and promote axonal regeneration (Rivieccio et al., 2009). Moreover, HDACis are also being developed for the treatment of various cancers, suggesting that they could treat chronic neurodegeneration without increasing the potential for tumorigenesis.

HDACis are known to selectively alter gene transcription by promoting histone acetylation (Grunstein, 1997). Moreover, they can increase the acetylation of many nonhistone proteins,

\footnotetext{
Received Nov. 8, 2012; revised Feb. 22, 2013; accepted March 18, 2013.

Author contributions: C.B., R.R.R., and B.L. designed research; C.B., G.D., M.A.R., K.M., and G.C. performed research; C.B., G.D., M.A.R., G.C., and B.L. analyzed data; C.B. and B.L. wrote the paper.

This work was supported by the New York State Spinal Cord Injury Research Program (Grant C019772), the Dr. Miriam and Sheldon G. Adelson Medical Research Foundation, and the Burke Medical Research Foundation. We thank Dr. Dianna Willis, Dr. Mariajose Metcalfe, and Rebecca Meyer for help and support in the preparation of this manuscript.

The authors declare no competing financial interests.

Correspondence should be addressed to Dr. Brett Langley, The Burke Medical Research Institute, 785 Mamaroneck Avenue, White Plains, NY 10605. E-mail: bc12002@med.cornell.edu.

DOI:10.1523/JNEUROSCI.5214-12.2013

Copyright $\odot 2013$ the authors $\quad 0270-6474 / 13 / 338621-12 \$ 15.00 / 0$
}

modifying their function or activity (Choudhary et al., 2009). A good example is the tumor suppressor p53, which drives many neurodegenerative processes (Morrison et al., 2003). p53 plays a central role in the DNA damage response, which contributes to neurodegeneration during cerebral ischemia, brain trauma, and age-related disease (Chang et al., 2012). After DNA damage, p53 accumulates and is activated to coordinate cellular responses that lead to DNA repair or the elimination of cells with extensive damage (Brooks and Gu, 2003; Culmsee and Mattson, 2005). The molecular basis underlying the choice between cell-cycle arrest and induction of apoptosis by p53 is not well understood. However, among the multiple posttranslational modifications of p53 that have been characterized, the acetylation of key lysine residues within the C-terminal region of p53 appears to be a determinant of activity (Olsson et al., 2007). Indeed, most studies suggest that acetylation stimulates p53 stabilization, sequencespecific binding activity, and activation of target genes ( $\mathrm{Gu}$ and Roeder, 1997; Zhao et al., 2006). Nevertheless, other evidence indicates that $\mathrm{p} 53$ activity depends on the specific lysines that are acetylated (Knights et al., 2006).

Uo et al. (2009) have highlighted the protective role of HDACis against p53-dependent apoptosis in neurons. However, the molecular targets of HDAC activity remain to be identified. Here, we demonstrate for the first time that HDAC inhibition prevents DNA damage-induced death in neurons by specifically modifying the acetylation pattern of $\mathrm{p} 53$, which decreases its transcriptional activity and suppresses the expression of pro-apoptotic PUMA. Furthermore, using mutants of p53, we identify lysines 381 and 382 as critical acetylation sites that prevent p53 from associating with chromatin, activating transcription, and inducing apoptosis in neurons. Finally, we make the significant finding 
that this outcome is specific to neurons by showing that acetylation at lysines 381 and 382 has diametric effects in tumor cells, where it induces p53-dependent activation of the PUMA promoter, and cell death. Together, the results presented herein suggest that $\mathrm{p} 53$ acetylation can be manipulated to prevent neuronal death without compromising tumor suppression.

\section{Materials and Methods}

Plasmids and general reagents. Plasmids encoding shRNA targeting Puma (shPUMA) and a random nucleotide sequence (shCTRL) were a kind gift from Dr. L. Aminova (University of Illinois, Urbana-Champaign, IL) (Aminova et al., 2008). Plasmids containing sequences for human p53 R175H DNA-binding mutant, p53 R175H K320R, p53 R175H K373R, and p53 R175H K382R double mutants were a kind gift from Dr. H.-G. Wang (Penn State College of Medicine, Hershey, PA) (Yamaguchi et al., 2009). pPUMAFrag1 was obtained from Addgene (plasmid 16591; Yu et al., 2001). pEGFP-C3 was obtained from Clontech (catalog \#6082-1).

The following HDAC inhibitors were purchased: trichostatin A (TSA; Enzo Life Sciences); sodium butyrate (Sigma-Aldrich); camptothecin (CPT; Sigma-Aldrich); etoposide (Enzo Life Sciences).

Antibodies. The following antibodies were obtained: anti- $\beta$ actin (AC-74; Sigma-Aldrich); anti-ATM (ab78; Abcam); anti-phospho S1981 ATM (MAB3806; Millipore); anti-COX IV (4844; Cell Signaling Technology); anti-cytochrome C (cytC; 456100; Invitrogen); anti-histone H4 (04-858; Millipore); anti-acetyl histone H3 (06-599; Millipore); anti-H2A.X (ab11175; Abcam); anti-phospho S139 H2A.X (05-636; Millipore); AntiMAP2 (AB5622; Millipore); anti-p21 (556430; BD Pharmingen); antihuman p53 (DO-1; Santa Cruz Biotechnology); anti-mouse p53 (M-19; Santa Cruz Biotechnology); anti-acetyl K317 p53 (ab62704; Abcam); antiacetyl K373 p53 (06-916; Millipore); anti-acetyl K379 p53 (2570; Cell Signaling); anti-acetyl K381 p53 (ab61241; Abcam); anti-phospho S15 p53 (9284; Cell Signaling Technology); anti-PUMA (3041; ProSci); anti-Sp1 (17-601; Millipore); anti- $\alpha$ tubulin (DM1A; Sigma-Aldrich); anti- $\beta$ III tubulin (TUJ-1; Covance).

Generation of p53 mutants by site-directed mutagenesis. Plasmids containing sequences for human p53 R175H DNA-binding mutant, p53 R175H K320R, p53 R175H K373R, and p53 R175H K382R were used as templates for site-directed PCR mutagenesis.

For each reaction, 50-100 ng of plasmidic template was mixed with $125 \mathrm{ng}$ of each HPLC-purified primer, $10 \mu \mathrm{M} \beta$ ine (Invitrogen), $0.2 \mathrm{~mm}$ dNTP, and 2.5 units of Pfu Ultra High Fidelity (Stratagene). Cycling conditions were as follows: $3 \mathrm{~min}$ at $95^{\circ} \mathrm{C}$, followed by 30 cycles of $30 \mathrm{~s}$ at $95^{\circ} \mathrm{C}, 1 \mathrm{~min}$ at $55^{\circ} \mathrm{C}$ and $1 \mathrm{~min} / \mathrm{kbp}$ template at $65^{\circ} \mathrm{C}$, and $5 \mathrm{~min}$ at $65^{\circ} \mathrm{C}$. Mutagenesis products were immediately digested with 20 units of DpnI (BioLabs) for $90 \mathrm{~min}$ at $37^{\circ} \mathrm{C}$. Two microliters of the reaction were used to transform heat shock competent Top10 bacteria following the manufacturer's protocol (Invitrogen), and positive clones were selected based on their resistance to ampicillin. Successful mutagenesis was confirmed by sequencing of the positive clones. Mutagenesis primers were designed as follows: K320Q (forward, CAGCCAAAGCAGAAACCACTGGATGG AGAATATTTCACCCTT; reverse, CAGTGGTTTCTGCTTTGGCTGG GGAGAGGAGCTGGTGTTGTT);K373Q (forward,AAGTCCAAACAG GGTCAGTCTACCTCCCGCCATAAAAAACTC; reverse, AGACTGAC CCTGTTTGGACTTCAGGTGGCTGGAGTGAGCCCT); K381Q (forward, TCCCGCCATCAAAAACTCATGTTCAAGACAGAAGGGCCTG AC; reverse, CATGAGTTTTTGATGGCGGGAGGTAGACTGACCCTT TTTGGA); K381R (forward, TCCCGCCATAGAAAACTCATGTTCAA GACAGAAGGGCCTGAC; reverse, CATGAGTTTTCTATGGCGGGAG GTAGACTGACCCTTTTTGGA); K382Q (forward, CGCCATAAACAA CTCATGTTCAAGACAGAAGGGCCTGACTCA; reverse, GAACATGA GTTGTTTATGGCGGGAGGTAGACTGACCCTTTTT); K381R, K382R (forward, CGCCATAGAAGACTCATGTTCAAGACAGAAGG GCCTGACTCA; reverse, GAACATGAGTCTTCTATGGCGGGAGGTA GACTGACCCCTTCT); K381Q, K382Q (forward, CGCCATCAACAA CTCATGTTCAAGACAGAAGGGCCTGACTCA; reverse, GAACATGA GTTGTTGATGGCGGGAGGTAGACTGACCCTGTTG).

Primary neurons and cell cultures. The HT22 murine hippocampal cell line was a kind gift from D. Schubert (Salk Institute, La Jolla, CA).

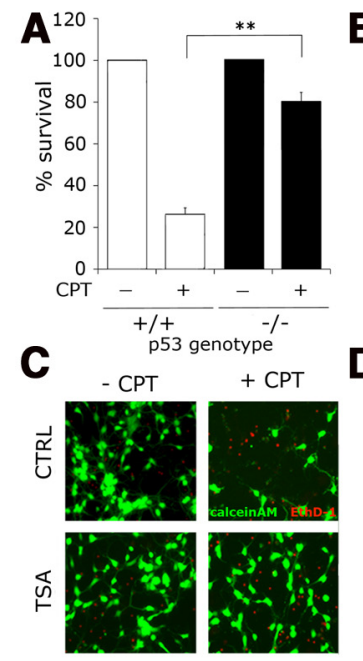

E
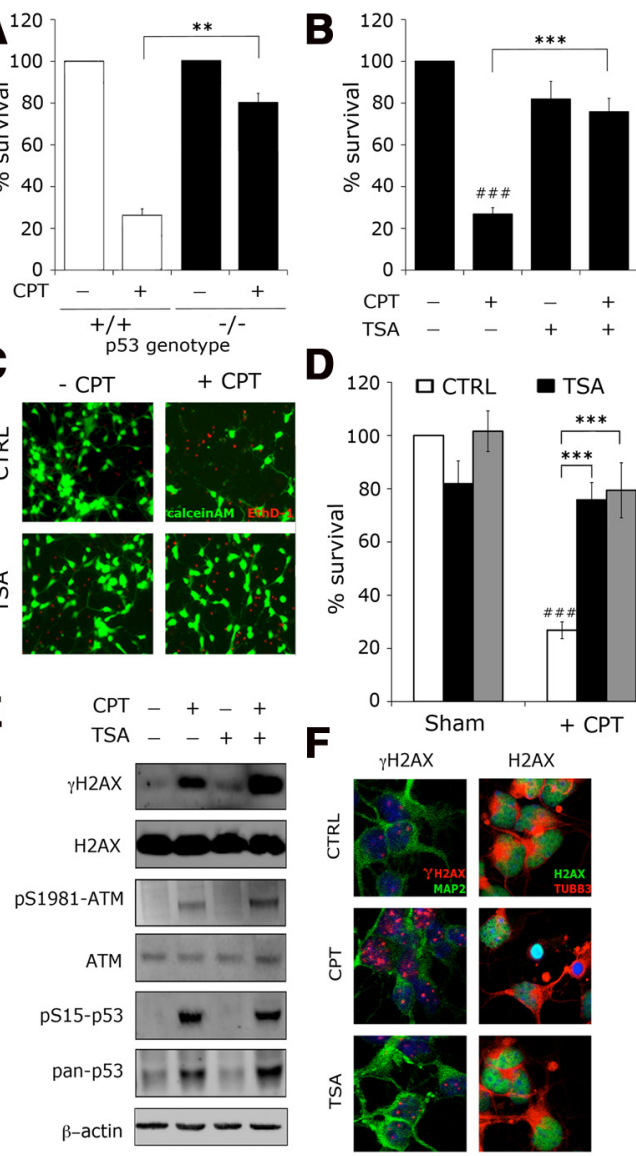

D
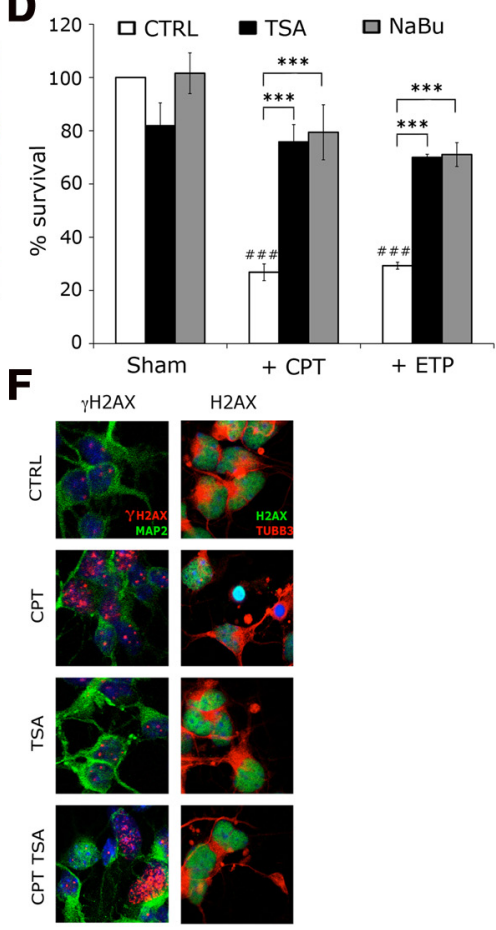

Figure 1. Pharmacological HDAC inhibition protects primary cortical neurons from DNA damage-induced death. A, Mouse $\mathrm{p} 53^{+/+}, \mathrm{p} 53^{-/+}$, and p53 ${ }^{-/-}$cortical neurons (E15.5) were treated with or without (PT $(10 \mu \mathrm{M})$ for $16 \mathrm{~h}$. Neuronal viability was measured by MTT assay. Error bars indicate SD of mean from six independent experiments. ${ }^{* *} p<0.01$, significant protection compared with $\mathrm{p} 53^{+/+}$(one-way ANOVA followed by Dunnett's multiplecomparisons test). $\boldsymbol{B}$, Neuronal viability measured by MTT assay after treatment of mouse primary cortical cultures (E15.5) with CPT $(10 \mu \mathrm{M})$ with or without TSA $(0.67 \mu \mathrm{M})$ for $16 \mathrm{~h}$. Error bars indicate $S D$ of mean from six independent experiments. ${ }^{* *} p<0.001$, significant difference between TSA- and non-TSA-treated groups; ${ }^{\# \#} p<0.001$, significant difference between CPT- and non-CPT-treated groups (two-way ANOVA followed by Bonferroni's test). C, Neuronal viability assessed by live/dead staining. Live cells are identified by green fluorescence (calcei$\mathrm{nAM}$ ); dead cells are identified by red fluorescence (ethidium homodimer, EthD-1). $\boldsymbol{D}$, Neuronal viability measured by MTT assay after treatment of mouse primary cortical cultures (E15.5) with CPT $(10 \mu \mathrm{M})$ or etoposide (ETP; $10 \mu \mathrm{m})$, with or without pan-HDAC inhibitor TSA $(0.67 \mu \mathrm{m})$ or the class-I HDAC inhibitor sodium butyrate ( $\mathrm{NaBu} ; 5 \mathrm{~mm}$ ) for $16 \mathrm{~h}$. Error bars indicate SD of mean from six independent experiments. ${ }^{* *} p<0.001$, significant difference between TSA- and non-TSA-treated groups or NaBu- and non-NaBu-treated groups; ${ }^{\# \#} p<0,001$, significant difference between CPT- and non-CPT-treated groups or ETP- and non-ETP-treated groups (two-way ANOVA followed by Bonferroni's test). $\boldsymbol{E}$, Immunoblot analysis of phosphorylated H2AX ( $\gamma$ H2AX), total H2AX, phosphorylated ATM (pS1981-ATM), total ATM, phosphorylated p53 (pS15-p53), and total p53 (pan-p53) in neurons treated with CPT (10 $\mu \mathrm{M})$ with or without TSA $(0.67 \mu \mathrm{M})$ for $8 \mathrm{~h} . \boldsymbol{F}$, Immunocytochemical analyses of $\gamma \mathrm{H} 2 \mathrm{AX}$ (red) and total $\mathrm{H} 2 \mathrm{AX}$ (green) in neurons treated with CPT $(10 \mu \mathrm{m})$ with or without TSA $(0.67 \mu \mathrm{M})$ for $8 \mathrm{~h}$. Anti-MAP2 (microtubule-associated protein 2; green) or anti-TUBB3 (Tubulin $\beta$-3; red) antibodies were used to define neurons. Nuclei were stained with DAPI (blue).

DLD-1 and HCT116 human cell lines were purchased from American Type Culture Collection. HT22 cells were propagated in DMEM, DLD-1 cells in RPMI-1640, and HCT116 cells in McCoy's 5a modified medium, all supplemented with $10 \%$ fetal calf serum and antibiotics (Invitrogen). 
A
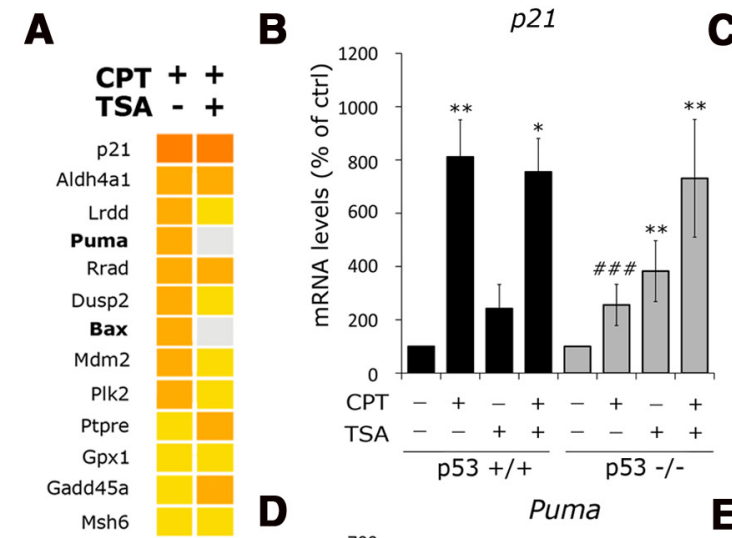

D

D1Bwg0212

Atf3

Rps27I

Noxa

Ppm2c

Xpc

Prodh

Nmu

Chst12

Fgf22

Pcna

Ltbp1

Tnfaip8

Sod2

Nr6a1

Ddb2

Acp 2

Smarcb 1

Mlh1

Kenma1

Stard4

Nck2

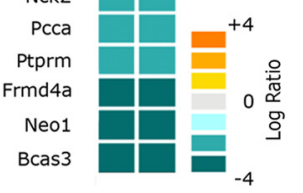

$-4$

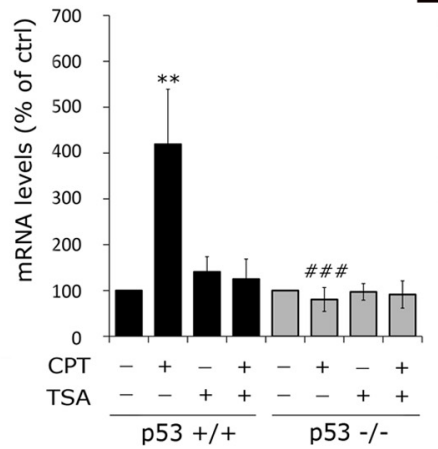

다

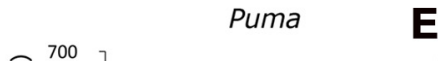

\section{E}
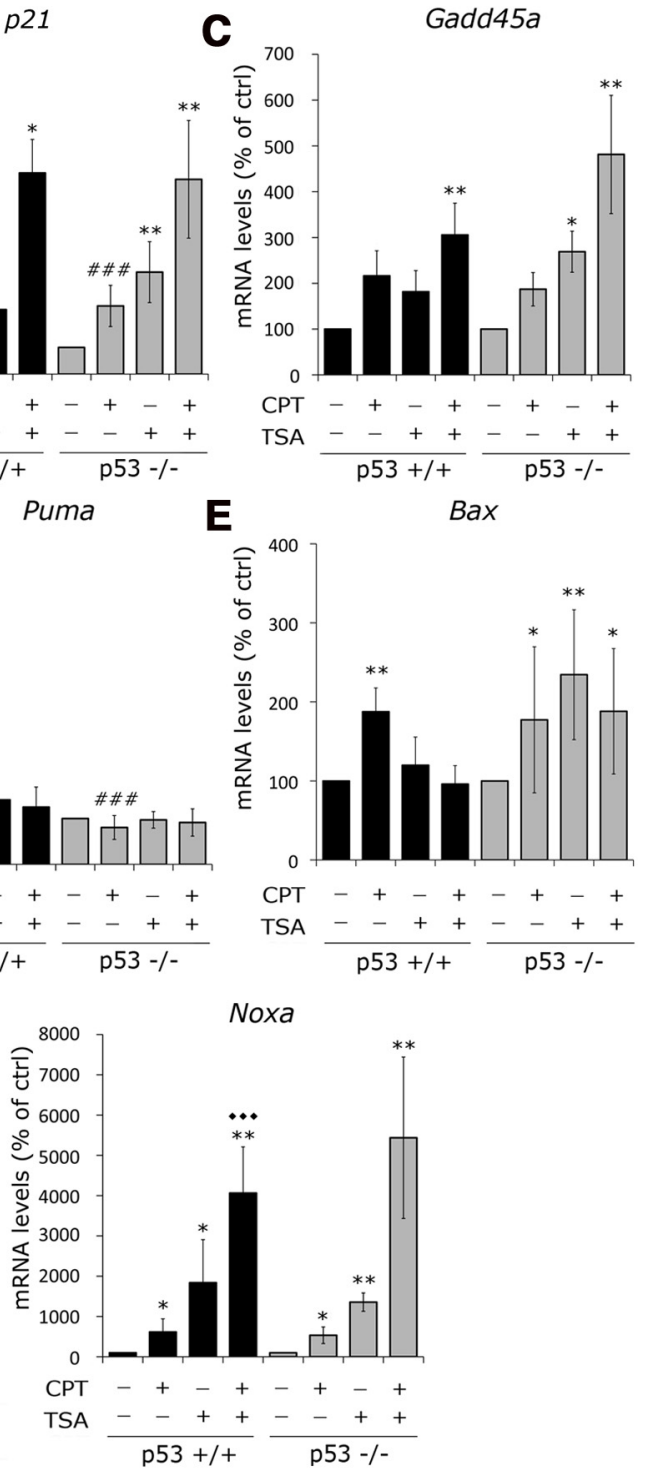

Figure 2. DNA damage and HDAC inhibition differentially regulate the transcription of known p53 target genes. $\boldsymbol{A}$, Heat map depicting gene expression in mouse primary cortical neurons (E15.5) treated with CPT (10 $\mu \mathrm{M})$ with or without TSA (0.67 $\mu \mathrm{M})$ for $12 \mathrm{~h}$. Shown are the 42 putative p53 gene targets that were significantly regulated in at least one condition compared with untreated control $(p<0.05)$. Expression profiles are displayed in descending order, based on induction level by (PT. $\boldsymbol{B}-\boldsymbol{F}$, Quantitative RT-PCR of select p53 gene targets in neurons from $\mathrm{p} 53^{+/+}$and $\mathrm{p} 53^{-/-}$mice treated with CPT (10 $\left.\mu \mathrm{m}\right)$ with or without TSA $(0.67 \mu \mathrm{m})$ for $8 \mathrm{~h}$. Error bars indicate SD of mean from five independent experiments. ${ }^{* *} p<0.01,{ }^{*} p<0.05$, significant difference compared with untreated control; $\bullet p<0.01$, significant difference compared with CPT alone (one-way ANOVA followed by Bonferroni's test); ${ }^{\# \#} p<0.001$, significant difference compared with knock-out p53 (two-way ANOVA followed by Bonferroni's test).

All animal surgeries and euthanasia were performed according to Institutional Animal Care and Use Committee guidelines under approved protocols. Male and female animals were used in this study. Embryonic day 15.5 (E15.5) pregnant wild-type (WT) C57BL/6J and CD-1 mice were obtained from Charles River. The B6.129S2-Trp53tm1Tyj/J (p53 deficient; C57BL/6J background) mouse line was obtained from The Jackson Laboratory and bred in house. The p53-null neurons were obtained from embryos derived from heterozygous breeding. Genotyping of each embryo was performed according to The Jackson Laboratory protocol for this strain. Neuronal cultures were prepared from E15.5 mice cortices by the papain dissociation method, as described previously (Langley et al., 2008). Cultures from the cortex of fetal mice at this stage of development are nearly $90 \%$ neuronal, the balance being predominantly glial. All cultures were plated at a density of $1 \times 10^{6}$ cells $/ \mathrm{ml}$ of Neurobasal medium (Invitrogen) supplemented with B27 (Invitrogen) and Glutamax (Life Technologies). There was no significant difference in the basal viability of the cultures prepared from wild-type or p53null embryos. All experiments described here were initiated $24 \mathrm{~h}$ after plating unless stated otherwise.

MTT (Promega) assay was performed as described by Langley et al. (2008). One-way or two-way ANOVA followed by the Dunnett's or Bonferroni's post hoc tests, respectively, were used to measure statistical significance. $p<$ 0.05 was considered to be statistically significant. The effectiveness of the MTT assays in measuring cell viability was confirmed by using the Live/Dead assay (Invitrogen) and fluorescence microscopy.

Electroporations. Electroporations were performed using the Amaxa Mouse Neuron Nucleofector kit as directed by the manufacturer (Lonza). Neuronal survival and transfection efficiency were determined in a series of experiments with different cell densities and amounts of a plasmid encoding eGFP, using the O-005 program on the Amaxa Nucleofector II (Lonza). Conditions were optimal for $4 \times 10^{6}$ cells and $4 \mu \mathrm{g}$ of plasmid per electroporation, with a survival and transfection efficiency of 70 and $40 \%$, respectively. To study neuronal morphology, images of random fields were captured $48 \mathrm{~h}$ after electroporation with the Axiocam MRm CCD camera (Carl Zeiss). Neurite length and number of processes were measured on cells expressing nontoxic p53 mutants and analyzed by using MetaMorph (Molecular Devices). No significant change was detected in terms of mean outgrowth per cell (eGFP, $89.4 \pm 8.21 \mu \mathrm{m}$; R175H, $80.76 \pm$ $7.90 \mu \mathrm{m}$; K381Q, $81.38 \pm 4.91 \mu \mathrm{m}$; K382Q, $74.55 \pm 6.92 \mu \mathrm{m})$ and number of processes (eGFP, $5.40 \pm 0.78 ; \mathrm{R} 175 \mathrm{H}, 4.71 \pm 0.87 ; \mathrm{K} 381 \mathrm{Q}$, $4.74 \pm 0.98 ; \mathrm{K} 382 \mathrm{Q}, 3.70 \pm 0.57$ ).

Protein purification, Western blotting, and immunocytochemistry. Protein lysates were prepared from cell cultures using RIPA buffer (Boston Bioproducts). Subcellular fractionation to isolate mitochondrial and cytosolic fractions was performed as described previously (Galli et al., 2008). Briefly, cells grown in $10 \mathrm{~cm}$ dishes were rinsed twice with $1 \times$ icecold PBS and centrifuged for $10 \mathrm{~min}$ at 5000 $\mathrm{rpm}$, and pellets were resupsended in $100 \mu \mathrm{l}$ of ice-cold MSHE buffer (225 mM mannitol, 70 mM sucrose, 2 mм HEPES, and 1 mM EGTA). Cell suspensions were then passed 60 times through a blunted $26 \mathrm{G}$ needle and centrifuged $10 \mathrm{~min}$ at $3300 \mathrm{rpm}$. Supernatants, containing cytosolic and mitochondrial fractions, were collected and centrifuged for an additional $10 \mathrm{~min}$ at $3300 \mathrm{rpm}$. Cleared supernatants were then centrifuged for $20 \mathrm{~min}$ at $10,000 \mathrm{rpm}$. After centrifugation, the supernatants, which contain the cytosolic fraction, were transferred to clean microtubes. The pellets, which contain the mitochondrial fraction, were washed once in $200 \mu \mathrm{l}$ of MSHE buffer, centrifuged for $20 \mathrm{~min}$ at 10,000 rpm, and resuspended in $20 \mu \mathrm{l}$ of MSHE buffer. Immunoblot analysis was performed using a Li-Cor Odyssey system as described by Langley et al. (2008).

For immunocytochemistry, primary antibodies were used in conjunction with AlexaFluor 488- or 594-conjugated secondary antibodies (Invitrogen) for detection. Slides were mounted with ProLong antifade Gold reagent with DAPI (Invitrogen). Immunostaining was examined under a Carl Zeiss Axiovert 200M microscope. 
Quantitative RT-PCR. Total RNA preparation from cultured cells was performed as described by Langley et al. (2008). RNA-to-Ct one-step real-time PCRs were performed on total RNA as a duplex reaction using 6-carboxyfluoresceinlabeled Puma, p21, Gadd45a, Bax and Noxa gene expression assays, and a VIC-labeled $\beta$-actin gene expression assay (Applied Biosystems).

Chromatin immunoprecipitation. Chromatin immunoprecipitations (ChIPs) were performed as described by Sleiman et al. (2011). Quantitative PCR was conducted with primers designed to amplify regions of the Puma promoter or the $p 21$ promoter, using SYBRGreen PCR Master-mix (Applied Biosystems). Promoter occupancy was determined relative to input. ChIP primers were designed as follows: $\mathrm{p} 21$ promoter, p53RE (forward, CCTTTCTATCAGCCCCAGAGGATAC C; reverse, GACCCCAAAATGACAAAGTGAC AA);Sp1BS (forward, GTCTGGCGCGGGCTTA GA; reverse, GTCGAGCTGCCTCCTTAT). The PUMA promoter was designed as follows: p53RE (forward, GACTCAGTGCACCCTGGCGTGC; reverse, GACAAGTCGGGGCTTGCAGTCG).

Promoter activity assays. Cells were transfected with pPUMA-Fragl (Yu et al., 2001) and p53 plasmids using Lipofectamine 2000 (Invitrogen) following the manufacturer's protocol. Lysates were prepared using Luciferase passive lysis buffer (Promega) $5 \mathrm{~h}$ (neuronal cultures) or $24 \mathrm{~h}$ (cell lines) after transfection. Luciferase activity was measured using a Luciferase reporter assay system (Promega) and an LMax II 384 luminometer (Molecular Devices). Values were normalized to total protein concentration (Bradford assay; Bio-Rad).

Microarray analysis. Total RNA was extracted from mouse primary cortical neurons (E15.5) after treatments with CPT $(10 \mu \mathrm{M})$ with or without TSA $(0.66 \mu \mathrm{M})$ for $12 \mathrm{~h}$, when the cells treated with CPT are committed to death. Three replicates were run per sample category. RNA was hybridized on Illumina Chips, and the results were analyzed as described previously (Sleiman et al., 2011). Quality assessment was achieved looking at the inter-array Pearson's correlation, and overall data coherence was measured by clustering based on top variant genes. Contrast analysis of differential expression was performed using the LIMMA package (Smyth et al., 2005). After linear model fitting, a Bayesian estimate of differential expression was calculated, and the threshold for statistical significance was set at $p<0.005$. Data analysis was aimed at assessing the effect of CPT treatment on control cells and cells treated with TSA. Since our preliminary data suggested a role for p53 in CPTinduced neuronal death, we focused our study on established p53 targets (Riley et al., 2008) that were spotted on the array and significantly regulated in at least one condition.

Statistical analyses. One-way or two-way ANOVA followed by the Dunnett's or Bonferroni's post hoc tests were used to measure statistical significance. $p<0.05$ was considered to be statistically significant. All experiments were performed a minimum of three times.

\section{Results}

HDAC inhibition protects primary cortical neurons from p53-dependent, DNA damage-induced apoptosis

HDACis are broadly neuroprotective in vivo, but the mechanisms underlying their beneficial effects remain unclear. Given the role of p53 in a number of neurodegenerative maladies, we used an in vitro model of neuronal DNA damage. In this model, cultured mouse primary cortical neurons are exposed to the topoisomerase-I inhibitor CPT, which results in the formation of double-strand breaks and p53-dependent apoptosis (Fig. 1A) (Morris and Geller, 1996). Treat-

\section{B}
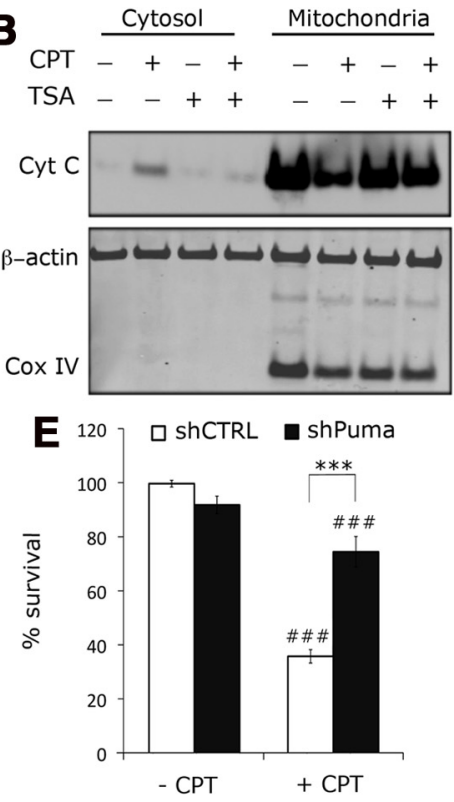

C
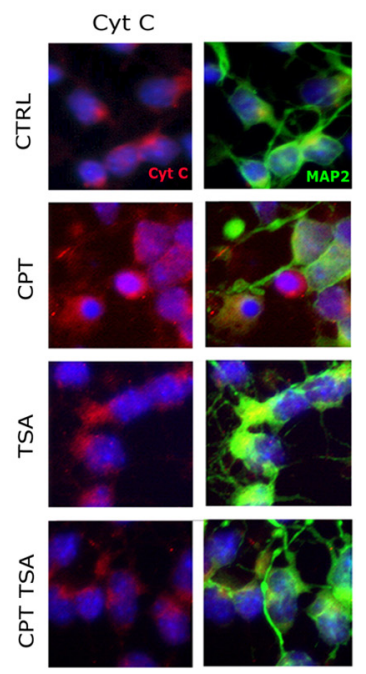

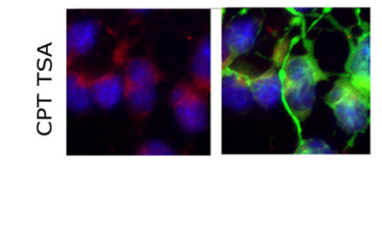

Figure 3. Abrogation of PUMA induction by TSA is sufficient to prevent DNA damage-induced neurodegeneration. $\boldsymbol{A}$, Immunoblot analysis of PUMA $\alpha$ and Cdkn1a (p21) in neurons treated with CPT (10 $\mu \mathrm{m})$ with or without TSA $(0.67 \mu \mathrm{m})$ for $8 \mathrm{~h}$. B, Immunoblot analysis C in cytosolic and mitochondrial fractions from neurons treated with CPT $(10 \mu \mathrm{m})$ with or without TSA $(0.67 \mu \mathrm{m})$ for $8 \mathrm{~h}$. COX IV, a ( 列 $(10 \mu \mathrm{m})$ for $16 \mathrm{~h}$. $\boldsymbol{E}$, Neuronal viability in $\boldsymbol{D}$ was measured by MTT assay. Error bars indicate SD of mean from three dependent experiments. ${ }^{* * *} p<0.001$, significant protection compared with shCTRL (one-way ANOVA followed by Bonferroni's test); between CPT- and non-CPT-treated groups (two-way ANOVA followed by Bonferroni's test).

ment of neuronal cultures with CPT led to widespread cell death within $16 \mathrm{~h}$ (Fig. $1 B, C$ ). However, combined treatment with the pan-HDACi TSA stimulated the survival of nearly $80 \%$ of the culture (Fig. $1 B, C ; p<0.001$ ). TSA was also able to protect neurons from death induced by the structurally distinct DNA-damaging agent etoposide. Additionally, the class I HDAC-specific inhibitor sodium butyrate could protect neurons from CPT- and etoposideinduced apoptosis (Fig. 1D).

To identify the molecular events leading to protection, we examined the effect of HDAC inhibition at multiple steps of the DNA damage response. This approach revealed that cotreatment with TSA did not prevent CPT-induced phosphorylation of the histone variant $\mathrm{H} 2 \mathrm{AX}(\gamma \mathrm{H} 2 \mathrm{AX}$; Fig. $1 E)$, which is known to occur within minutes of DNA damage and facilitate the accumulation of DNA repair and checkpoint proteins to the break site (Kinner et al., 2008). Furthermore, TSA had no effect on the chromatin distribution of $\gamma \mathrm{H} 2 \mathrm{AX}$ or H2AX (Fig. $1 F$ ). Similarly, TSA did not prevent the activation of ataxia-telangectasia mutated (ATM) by autophosphorylation on S1981 (S1987 in mouse; Bakkenist and Kastan, 2003), nor did it prevent the ATM-dependent phosphorylation of p53 on S15 (S18 in mouse; Fig. 1E). Consistent with the role of phosphorylation in p53 stabilization (Banin et al., 1998), TSA did not prevent p53 accumulation after CPT treatment (Fig. $1 E)$. Together, these results suggest that HDAC inhibition mediates protection by regulating molecular events of the DNA damage response that are downstream of p53 stabilization.

\section{TSA prevents the recruitment of p53 to Puma and $p 21$ promoters in neurons}

Since HDAC activity modulates gene expression by inducing or repressing transcription in a promoter-specific manner (Nusinzon and Horvath, 2005), we performed a microarray analysis of 
A

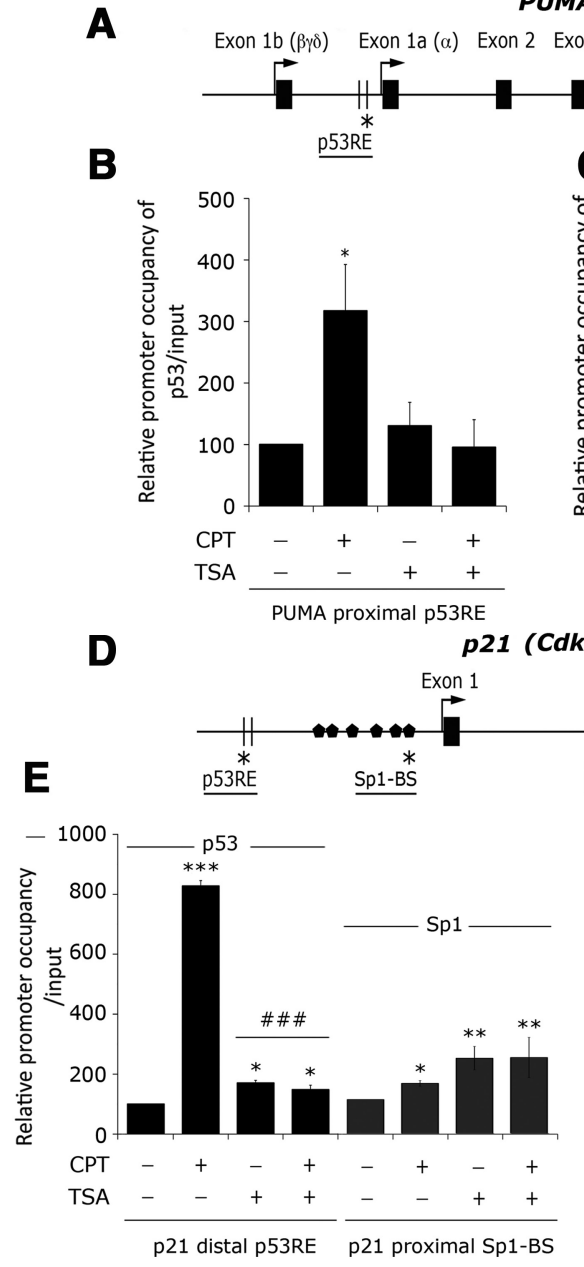

PUMA

3

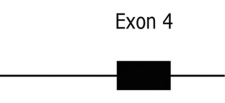

C

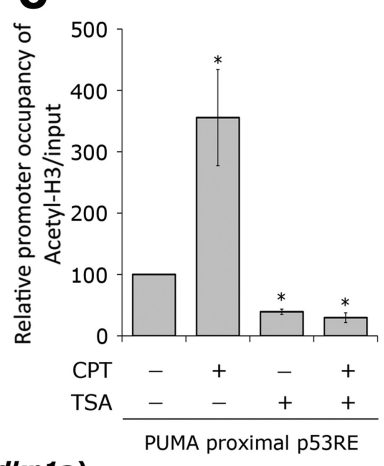

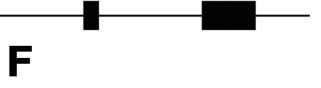

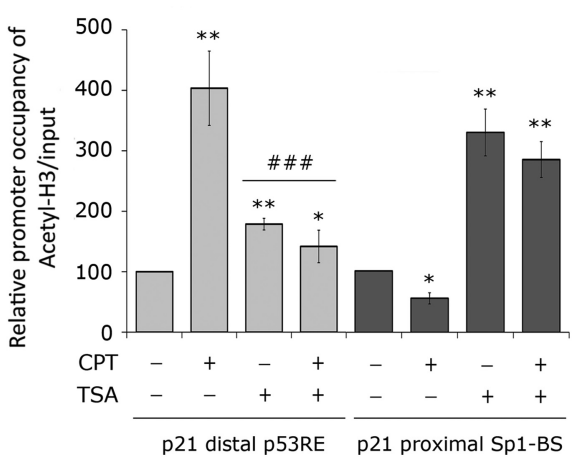

Figure 4. HDAC inhibition by TSA abrogates DNA damage-induced binding of $\mathrm{p} 53$ to Puma and $p 21$ promoters, but it promotes the recruitment of Sp1 to the 21 promoter. $A$, Schematic of PUMA gene. The human gene contains three coding exons (exons $2-4$ ) and two noncoding exons (exons $1 \mathrm{a}$ and $\mathrm{b}$ ), which are conserved in mouse. Two $\mathrm{p} 53$ response elements (p53RE) are found in the regulatory region of both human and mouse genes. The asterisk indicates PCR primer binding sites. $\boldsymbol{B}, \boldsymbol{C}, \mathrm{ChlPs}$ for p53 $(\boldsymbol{B})$ and acetylated histone $\mathrm{H3}(\boldsymbol{C})$ in extracts from mouse primary cortical neurons (E15.5) treated with $(\mathrm{PT}(10 \mu \mathrm{M})$ with or without TSA $(0.67 \mu \mathrm{M})$ for $8 \mathrm{~h}$. Promoter occupancy was determined by quantitative real-time PCR using primers specific for p53RE (defined in A). Error bars indicate SD of mean from three independent experiments. ${ }^{*} p<0.05$, significant difference compared with untreated control (one-way ANOVA followed by Bonferroni's test). D, Schematic of $p 21$ (Cdkn1a) gene. The human gene contains two coding exons (exons 2 and 3) and one noncoding exon (exon 1), which are conserved in mouse. Two p53 response elements (p53RE) and six Sp1 binding sites (Sp1-BS) are found in the regulatory region of both human and mouse genes. Asterisks indicate PCR primer binding sites. E, F, ChlPs for p53, Sp1, and acetylated histone H3 in extracts from neurons treated with CPT (10 $\mu \mathrm{M})$ with or without TSA $(0.67 \mu \mathrm{m})$ for $8 \mathrm{~h}$. Promoter occupancy was determined by quantitative PCR using primers specific for p53RE or Sp1-BS (defined in D). Error bars indicate SD of mean from three independent experiments. ${ }^{* * *} p<0.001,{ }^{* *} p<0.01,{ }^{*} p<0.05$, significant difference compared with untreated control; $\# \#$ $p<0.001$, significant difference compared with CPT (one-way ANOVA followed by Bonferroni's test).

the neuronal transcriptome after a $12 \mathrm{~h}$ treatment with CPT or CPT and TSA combined. A focused study on established p53inducible targets (Riley et al., 2008) revealed 42 genes that were regulated in either condition, of which 20 were induced by CPT (Fig. 2A). Expression analyses by quantitative RT-PCR (qRTPCR) in WT neurons confirmed the pattern of regulation identified in the microarray, whereby CPT induced the expression of the cellcycle arrest genes $p 21$ and Gadd $45 a$, which was not prevented by TSA (Fig. $2 B, C ; p<0.05$ and $p<0.01$ ). CPT also induced two proapoptotic genes, Puma and Bax (Fig. $2 D, E ; p<0.01$ ). In contrast to p21 and Gadd45a, CPT-induced Puma and Bax expression was abrogated by TSA. Interestingly, this effect of TSA was restricted to these two genes. Indeed, the CPT-induced expression of Noxa, an-

other pro-apoptotic gene belonging to the $\mathrm{BH} 3$-only family, was enhanced by cotreatment with TSA (Fig. 2A, F; $p<0.001$ ).

To confirm a direct role of p53 in the expression of p21, Gadd45a, Puma, Bax, and Noxa, qRT-PCRs were performed in p53-null cortical neurons treated with CPT with or without TSA (Fig. $2 B-F$ ). Surprisingly, the CPT-induced expression of Noxa, Gadd45a, and Bax was not altered in the absence of p53, which might reflect the contribution of other transcription factors of the p53 family, p63 and p73 (Flores et al., 2002). In contrast, the induction of Puma by CPT was completely lost in p53-null neurons $(p<0.001)$, and the expression of $p 21$ was significantly reduced $(p<0.001)$, although not suppressed, suggesting it may be coregulated by additional transcription factors. Immunoblot analysis of Puma and p21 protein levels in WT neurons revealed the same regulation profile as their transcripts in response to DNA damage and HDAC inhibition (Fig. 3A).

The pro-apoptotic activity of Puma relies on its critical role in mitochondrial outer membrane permeabilization and cytC release (Jabbour et al., 2009). Consistent with this, immunoblot and immunocytochemical analysis revealed that CPT induced the translocation of cytC to the cytosolic fraction (Fig. $3 B, C$ ). As predicted by the finding that TSA abrogates Puma induction, cotreatment with TSA prevented the cytosolic translocation of cytC (Fig. 3A-C). To confirm that Puma is a key mediator of apoptosis in neurons, cortical neurons were electroporated with plasmids encoding shPuma or shCTRL and examined for survival after CPT treatment. Coinciding with Puma depletion (Fig. 3D), neurons were effectively protected from CPT-induced death (Fig. 3E; $p<0.001)$.

To understand how HDAC inhibition prevents the p53-dependent induction of Puma and $p 21$ in neurons after CPT treatment, ChIP analysis was performed. Determination of p53 binding at characterized p53 response elements in Puma and p21 promoters (Fig. 4A,D) demonstrated an increase in p53 occupancy after CPT treatment (Fig. $4 B, E ; p<0.05$ and $p<0.001$ ). Consistent with promoter activation, ChIP analysis for acetyl-histone $\mathrm{H} 3$ showed higher levels of acetylation within these regions (Fig. 3C,F; $p<0.05$ and $p<0.01$ ). However, cotreatment with TSA disrupted the CPT-induced increase in p53 occupancy (Fig. $4 B, E$ ), as well as the increase in histone $\mathrm{H} 3$ acetylation (Fig. 4C,F). Given our observation that TSA treatment alone induced the expression of p21 independent of p53 (Fig. $2 B$ ), we also examined Sp1 occupancy at well documented Sp1binding sites (Fig. 4D). ChIP analysis showed that TSA enhanced $\mathrm{Sp} 1$ binding and histone $\mathrm{H} 3$ acetylation at the proximal region of the p21 promoter (Fig. 4E, F; $p<0.001$ ). 
Together, our results suggest that the HDACi-mediated neuroprotection from DNA damage-induced death is mediated by the regulation of p53 transcriptional activity, whereby 553 binding to the Puma promoter is lost, leading to the suppression of Puma expression. Moreover, we show that whereas p53 induction of p21 expression is similarly suppressed by HDAC inhibition, Spl-dependent transcription was promoted.

\section{DNA damage and HDAC inhibition differentially modulate p53 acetylation in neurons}

Specific acetylation of p53 within its C-terminal region is known to regulate its stability and transcriptional activity, thereby facilitating active transcription of cell-cycle arrest, survival, or apoptotic gene programs (Olsson et al., 2007) (Fig. 5A). However, the effects of acetylation and deacetylation on p53 activity seem to be cell-type dependent, and little is known about their consequence in neurons.

To examine whether changes in p53 acetylation by HDACi might account for the loss of Puma expression, we examined acetylation changes in the C-terminal region of p53 in neurons treated with CPT and TSA (Fig. 5B). Immunoblot analysis determined that CPT treatment increased the level of p53 acetylated at K373 and decreased the level of p53 acetylated at K381. In contrast, TSA treatment increased the levels of p53 acetylated at K320, K381, and K382. When neurons were treated with both CPT and TSA, p53 acetylation levels were increased at all sites. Together, these results indicate that $\mathrm{K} 373$ acetylation and K381 deacetylation in p53 correlate with the DNA damage response and apoptosis in neurons, whereas acetylation of p53 at K320, K381, and K382 correlates with HDAC inhibitor-mediated neuroprotection.

The nuclear import or retention of p53 is essential for its normal function in growth inhibition (Knippschild et al., 1996) and induction of apoptosis (Ryan and Clarke, 1994). It is facilitated by the nuclear localization signal (NLS) located in the C-terminal part of the protein, be-

tween amino acids 305 and 322 (Liang et al., 1998). Since K320 lies within the NLS (Fig. 5A), we used immunocytochemistry to determine whether TSA alters the distribution of p53 in neurons (Fig. 5C). Consistent with p53 activation, the level of p53 phosphorylated at S15 was increased in the nucleus after treatment with CPT. TSA neither changed the level of phosphorylated p53 nor its localization. Instead, increased immunoreactivity for p53 acetylated at K320, K381, or K382 was localized to the nuclei of neurons treated with CPT and TSA, confirming that acetylation of these lysines does not prevent nuclear localization of $\mathrm{p} 53$.
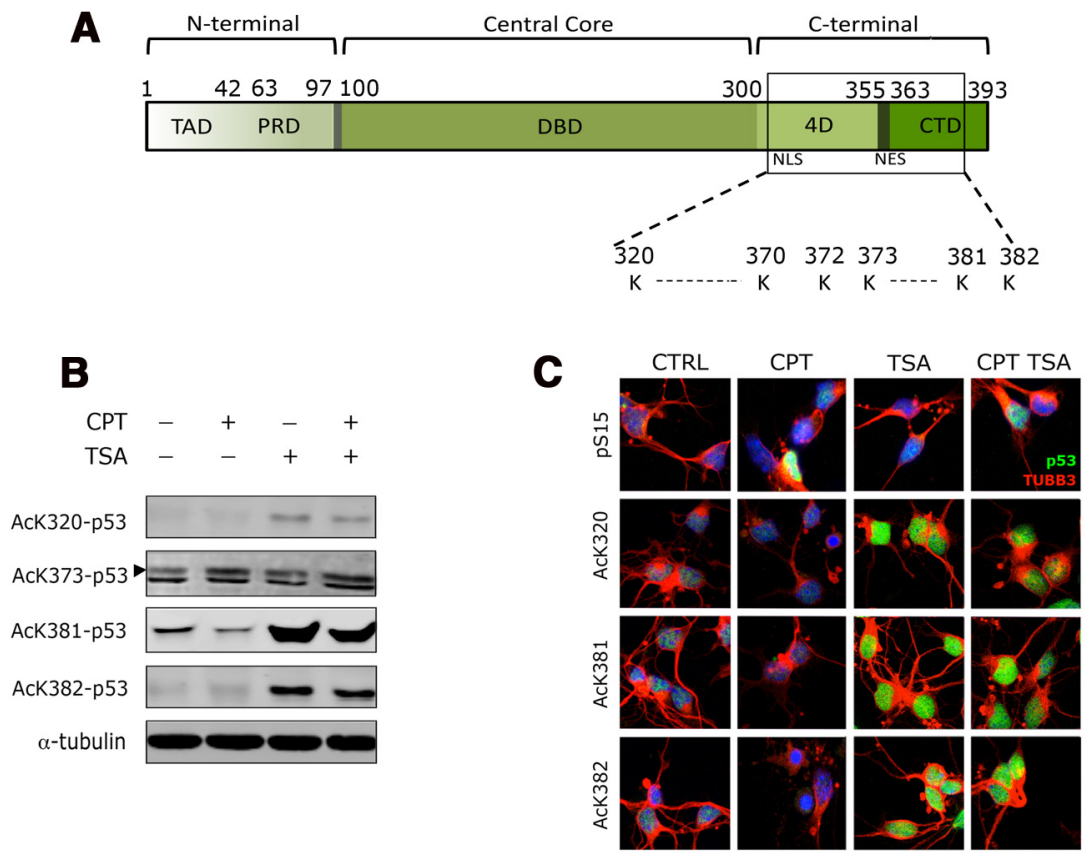

p53 C-terminus

E
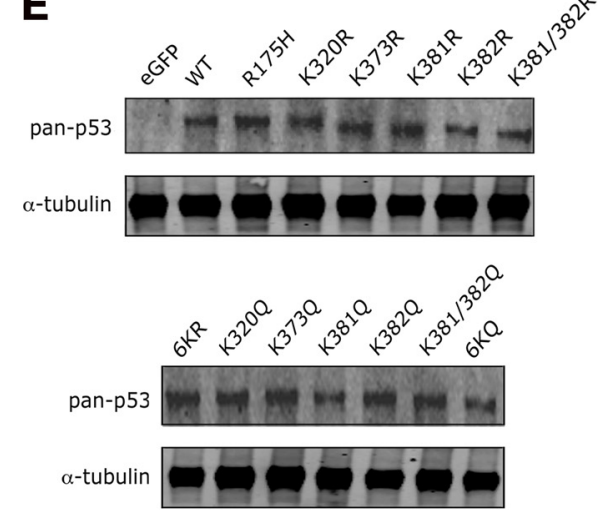

Figure 5. CPT-induced DNA damage and HDAC inhibition by TSA differentially modulate $\mathrm{p} 53$ acetylation. $A$, Schematic of $p 53$ protein. Human p53 contains 393 amino acids, organized into three functional domains, that are conserved in mouse. The $\mathrm{N}$ terminus includes the transactivation domain (TAD) and the proline-rich domain (PRD). The central region contains the DNAbinding domain (DBD). The C-terminal region includes the tetramerization domain of $\mathrm{p} 53$ (4D), the C-terminal regulatory domain (CTD), and nuclear localization and export signals (NLS and NES). Lysines in the C-terminal region can be acetylated, affecting p53 protein stability and function. B, Immunoblot analysis of acetylated K320-p53, acetylated K373-p53, acetylated K381-p53, and acetylated K382-p53 (respectively, K317, K370, K376, and K379 in mouse) in mouse primary cortical neurons treated with (PT (10 $\mu \mathrm{M})$ with or without TSA $(0.67 \mu \mathrm{M})$ for $8 \mathrm{~h}$. C, Immunocytochemical analyses of phosphorylated p53 (pS15), acetylated K320-p53, without TSA $(0.67 \mu \mathrm{m})$ for $8 \mathrm{~h}$. TUBB3 (Tubulin $\beta$-3; red) was used to define neurons. Nuclei were stained with DAPI (blue). $\boldsymbol{D}$ scheme showing the lysine-to-arginine (deacetylation-mimic) and lysine-to-glutamine (acetylation-mimic) human p53 mutants generated and used in this study. The circle represents lysine substitution with arginine or glutamine. $\boldsymbol{E}$, Immunoblot analysis of human $\mathrm{p} 53$ shows expression of wild-type p53 (WT), DNA-binding mutant p53 (R175H), or the different p53 acetylation mutants in mouse cortical neurons. eGFP was used as an electroporation control.

Acetylation at lysines 381 and 382 , but not 373 , is sufficient to prevent the pro-apoptotic activity of $\mathrm{p} 53$ in neurons

To investigate a causative role of p53 acetylation on neuronal survival, we generated a series of p53 mutants bearing glutamine (Q; which mimics acetylated lysine) or arginine ( $\mathrm{R}$; which mimics deacetylated/nonacetylatable lysine) substitutions at lysines 320, 373, 381, and 382 (Fig. 5D). The ability of the p53 acetylation mutants to induce neuronal death was compared with a WT p53 and a DNA-binding-deficient p53 (R175H). All p53 constructs showed similar levels of expression (Fig. 5E), and all were detected in the nuclei of neurons (data not shown). As expected, 


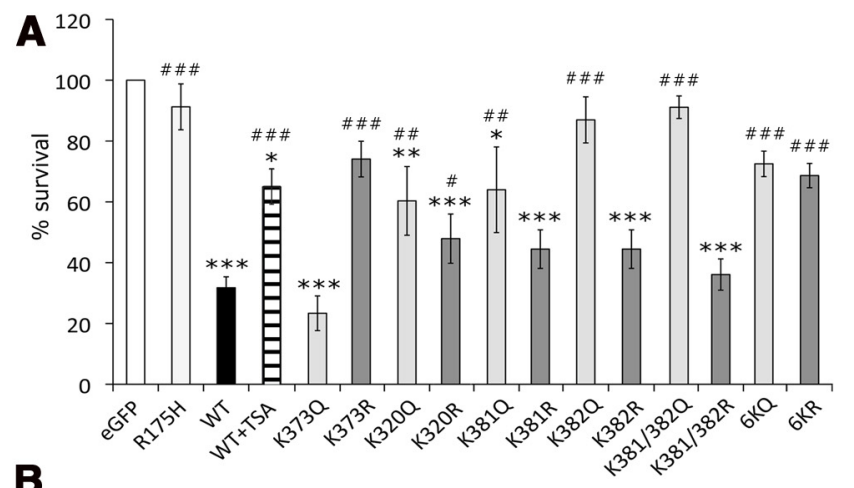

B
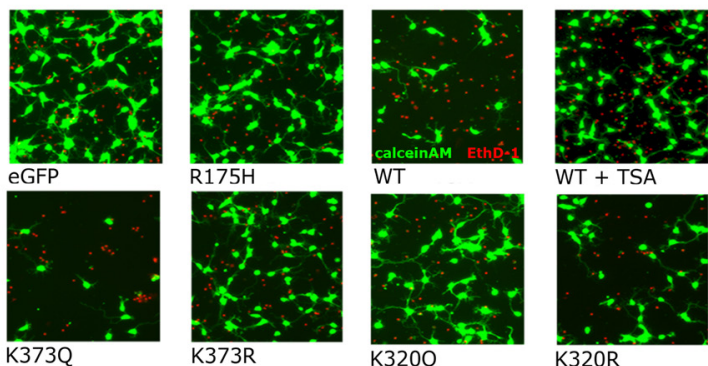

K373Q

K373R
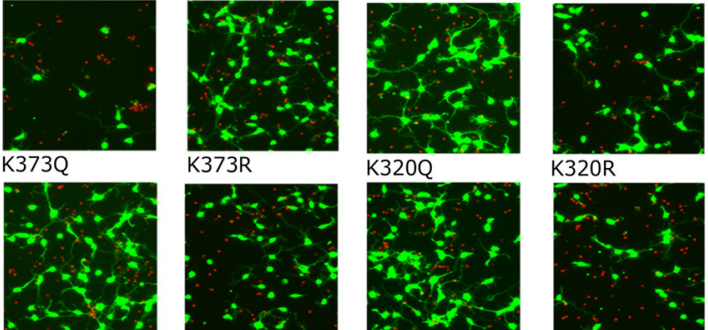

$\mathrm{K} 381 \mathrm{Q}$
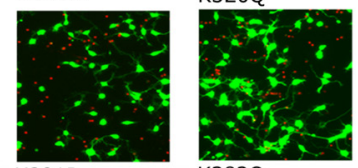

K320R

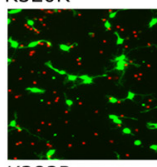

$\mathrm{K} 382 \mathrm{Q}$

$\mathrm{K} 382 \mathrm{R}$

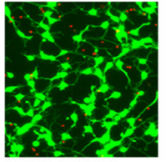

K381/382Q

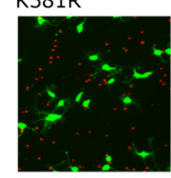

K381/382R
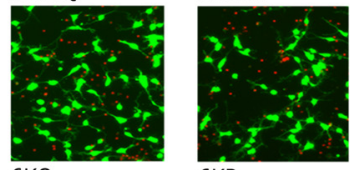

6KQ

$6 K R$

C

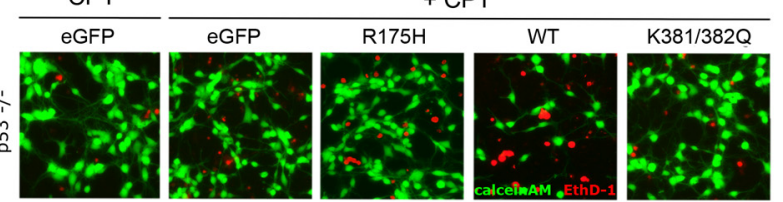

Figure 6. Acetylation of $p 53$ on lysines 381 and 382 abrogates its ability to induce apoptosis in neurons. $\boldsymbol{A}$, Neuronal viability measured by MTT assay of cortical neurons prepared from p53 ${ }^{-1-}$ mice (E15.5) $48 \mathrm{~h}$ after electroporation with plasmid DNA encoding the DNA-binding mutant (R175H), WT, or different acetylation mutants of $\mathrm{p} 53$. Neurons expressing WT $\mathrm{p} 53$ were treated with or without TSA $(0.67 \mu \mathrm{M})$. eGFP was used as an electroporation control. Error bars indicate SD of mean from three independent experiments. ${ }^{* *} p<0.001,{ }^{* *} p<0.01,{ }^{*} p<$ 0.05 , significant difference compared with eGFP; ${ }^{\# \#} p<0.001,{ }^{\#} p<0.01,{ }^{\#} p<0.05$, significant difference compared with wild-type p53 (WT) (one-way ANOVA followed by Bonferroni's test). $\boldsymbol{B}$, Viability of $\mathrm{p} 53$-null neurons assessed by live/dead staining under the conditions described in $\boldsymbol{A}$. Live cells are identified by green fluorescence (calceinAM), whereas dead cells are identified by red fluorescence (ethidium homodimer, EthD-1). C, Viability of p53-1neurons measured by live/dead staining after electroporation with plasmid DNA encoding DNAbinding mutant (R175H), WT, or K381/382Q acetylation-mimic of $\mathrm{p} 53$ and treated with CPT (10 $\mu \mathrm{m})$. eGFP was used as a control.

overexpression of $\mathrm{R} 175 \mathrm{H}$ was not toxic when compared with neurons expressing an eGFP control (Fig. 6A,B). In contrast, neurons overexpressing exogenous WT p53 displayed a significant $68 \%$ death (Fig. $6 A ; p<0.001$ ), which could be prevented by TSA treatment $(p<0.001)$. Consistent with our findings that DNA damage induces p53 acetylation at K373, the overexpression of the K373Q acetyl-mimic showed significant toxicity (Fig. $6 A, B ; p<0.001$ ), whereas the overexpression of the K373R nonacetylatable mutant was significantly less toxic than WT p53 (Fig.
A

PUMA Frag1-Luc
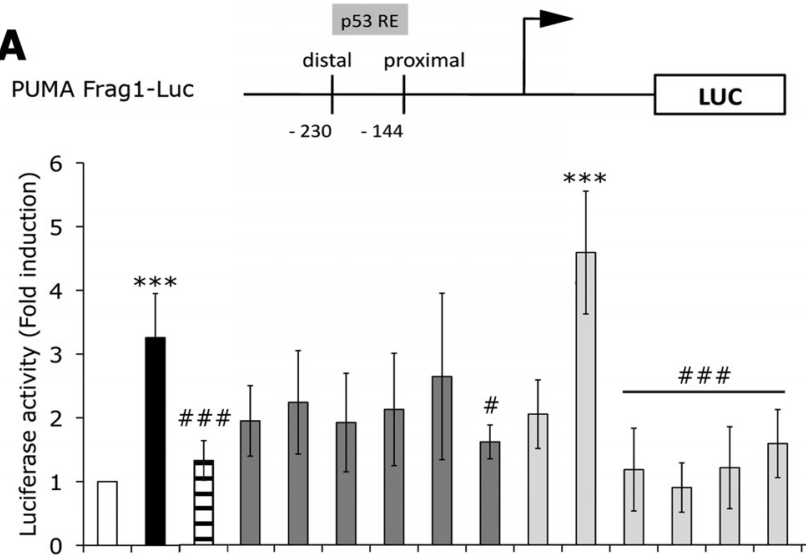

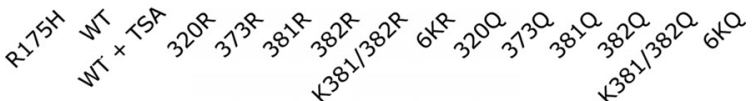

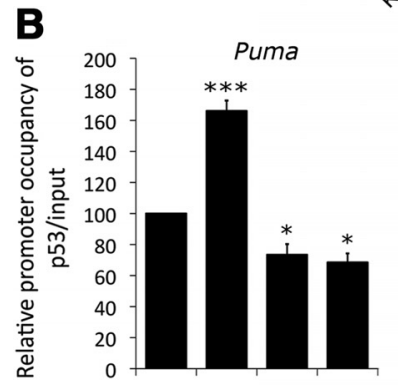

C

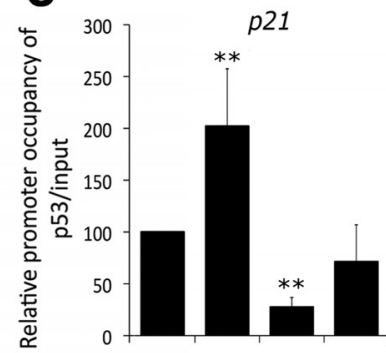

$R 1^{15 H} w^{\top} \times 382^{0} \times 38^{20}$

D

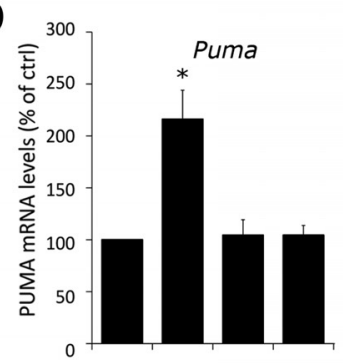

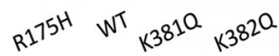

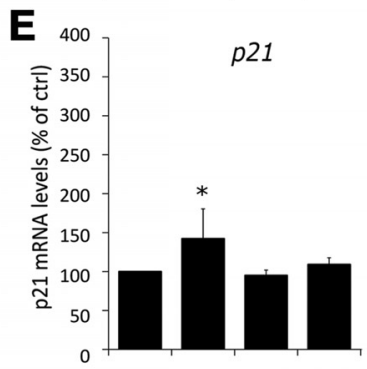

$R 17 H^{5 H} W^{\top} \times 3810$ K $33^{820}$

Figure 7. Acetylation of lysines 381 and 382 abrogates the transactivating activity of $p 53$ in neurons. $A$, Luciferase reporter assay of plasmid DNA encoding a fragment of the human PUMA proximal promoter (PUMA Frag1-Luc) in $\mathrm{p5} 3^{-1-}$ primary cortical neurons. Promoter reporter plasmid was cotransfected with DNA-binding mutant (R175H), WT, or different acetylation mutants of $p 53$. WT p53-transfected neurons were treated with or without TSA $(0.67 \mu \mathrm{M})$. Error bars indicate SD of mean from five independent experiments. ${ }^{* * *} p<0.001$, significant difference compared with $\mathrm{R} 175 \mathrm{H}$; ${ }^{\# \# \#} p<0.001$, $p<0.05$, significant difference compared with wild-type p53 (WT) (one-way ANOVA followed by Bonferroni's test). B, C, Chromatin immunoprecipitations for human $\mathrm{p} 53$ in extracts from mouse primary cortical neurons electroporated with p53 plasmids: R175H, WT, or the acetyl-mimics K381Q and K382Q. Promoter occupancy was determined by quantitative $P C R$ using primers specific for $p 53 R E$ (defined in Fig. $4 A$ ). Error bars indicate SD of mean from three independent experiments. ${ }^{* * *} p<0.001$; ${ }^{* *} p<0.01$; ${ }^{*} p<0.05$, significant difference compared with R175H (one-way ANOVA followed by Dunnett's multiple-comparisons test). D, E, Quantitative RT-PCR of Puma (D) and p21 (E) expression in neurons electroporated with p53 plasmids: R175H, WT or the acetyl-mimics K3810 and K382Q. Error bars indicate SD of mean from three independent experiments. ${ }^{*} p<0.05$, significant difference compared with R175H (one-way ANOVA followed by Dunnett's multiplecomparisons test).

$6 A, B ; p<0.001)$. In contrast to $\mathrm{K} 373$, acetyl-mimic mutations of $\mathrm{K} 320$, K381, and K382, all of which are acetylated with TSA treatment and correlate with protection, significantly reduced the toxicity associated with p53 overexpression. Indeed, K320Q and 
K381Q overexpression showed significantly less toxicity than that of WT p53 (Fig. 6A, $B$; $p<0.01)$. Furthermore, K382Q overexpression was not toxic, suggesting that acetylation at this site is sufficient to prevent p53 pro-apoptotic activity in neurons. Consistent with this, mutation of these lysines to the deacetylation-mimic arginine (K320R, $\mathrm{K} 381 \mathrm{R}$, and $\mathrm{K} 382 \mathrm{R}$ ) did not abrogate the induction of cell death (Fig. 6A,B). To study the effects of combinatorial acetylation, two additional mutants were generated, one bearing substitutions at $\mathrm{K} 381$ and $\mathrm{K} 382$ (K381/382R/Q) and one bearing substitutions at all of the C-terminal lysines $(6 \mathrm{KR} / \mathrm{Q}$; Fig. 5D). Neurons overexpressing the K381/ 382 mutants displayed the same survival profile as those overexpressing the K382 mutants. Importantly, 6KQ overexpression was significantly less toxic than that of WT p53 (Fig. $6 A, B ; p<0.001$ ), indicating that K320Q, K381Q, and K382Q substitutions could overcome the pro-death activity of K373Q. Overexpression of the converse mutant $6 \mathrm{KR}$ was not different from that of the single mutant K373R, which highlights the role of $\mathrm{K} 373$ acetylation in p53dependent neuronal death.

To study the role of p53 acetylation in the context of DNA damage-induced neuronal death, we studied the ability of the K381/382Q double mutant to restore apoptosis of p53-null neurons treated with CPT (Fig. 6C). Although significant death was apparent in WT p53-expressing neurons after CPT treatment, neither the DNA-binding mutant $\mathrm{R} 175 \mathrm{H}$ nor the acetylation-mimic K381/382Q could mediate CPT-induced death, indicating the importance that specific acetylation of these lysines plays in TSA-mediated neuroprotection.

Given the role of Puma induction in CPT-induced neuronal death (Fig. 3E), the p53 acetylation mutants were screened for their ability to transactivate a PUMA promoter upstream of the firefly Luciferase gene. In p53-null neurons, overexpressed WT p53 activated the PUMA promoter by more than threefold compared with the DNA binding-deficient R175H (Fig. 7A; $p<0.001$ ), which could be prevented by TSA treatment. The nonacetylatable mutants K320R, K373R, K381R, K382R, K381/382R, and 6KR, showed a decreased capacity to activate the PUMA promoter. Consistent with our survival data (Fig. 6A, B), the K373Q mutant showed a transactivation activity similar to that of WT p53. In contrast to this, K381Q, K382Q, or K381/382Q, which comprise the sites acetylated by HDAC inhibition, abolished the transactivating activity of p53. Likewise, the $6 \mathrm{KQ}$ acetylation-mimic was not able to transactivate the PUMA promoter (Fig. 7A), supporting the observation that K381Q and $\mathrm{K} 382 \mathrm{Q}$ substitutions could overcome the pro-death activity of K373Q (Fig. 6A,B).

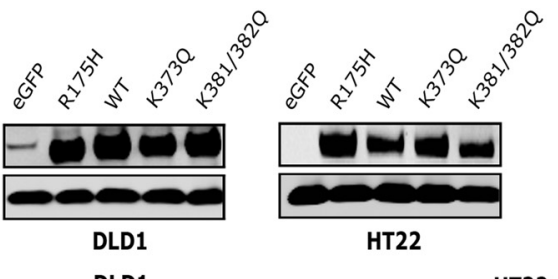

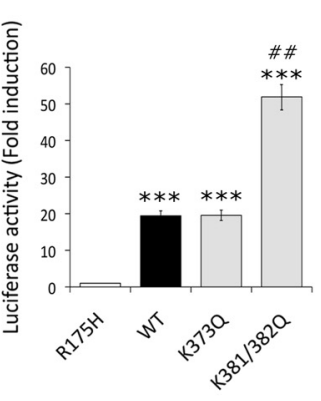

DLD1

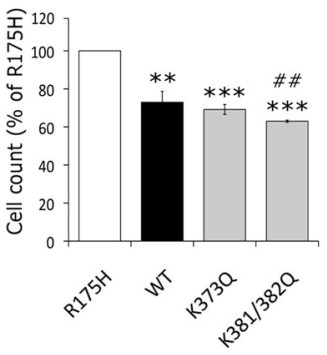

WT

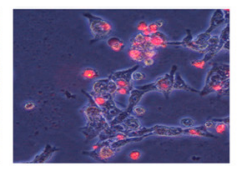

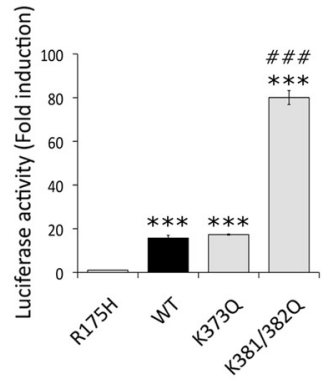

HT22

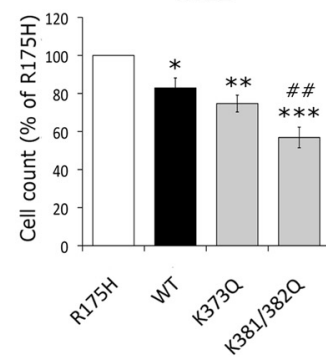

$\mathrm{K} 381 / 382 \mathrm{Q}$

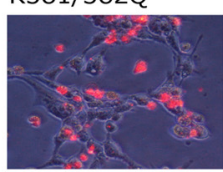

Figure 8. Acetylation of lysines 381 and 382 promotes the pro-apoptotic functions of p53 in proliferating tumor cell lines. $\boldsymbol{A}$, HCT116, DLD1, and HT22 cells were transfected with an equal amount of plasmid DNA encoding wild-type human p53 (WT), DNA-binding mutant p53 (R175H), or the 533 acetylation mutants K3730 and K381/382Q. Immunoblot analysis was performed on transfection control. $\boldsymbol{B}$, Luciferase reporter assay of plasmid DNA encoding a fragment of the human PUMA proximal promoter (PUMA Frag1-Luc) in human colorectal carcinoma cell lines HCT116 and DLD-1 and in mouse hippocampal cell line HT22. Promoter utants of $\mathrm{p53}$. Error bars indicate SD of mean from three independent experiments. ${ }^{* * *} p<0.001$, significant difference mpared with $\mathrm{R} 175 \mathrm{H} ;{ }^{\# \#} p<0.001,{ }^{\# \#} p<0.01$, significant difference compared with WT (one-way ANOVA followed by (Cell viability measured by MTT assay of HCT116, DLD-1, and HT22 cultures $24 \mathrm{~h}$ after transfection with R175H, WT, K373Q, or K381/3820 acetylation mutants of p53. Error bars indicate SD of mean from three independent experiments. with WT (one-way ANOVA followed by Bonferroni's test). D, HCT116 cell death assessed by ethidium homodimer staining (EthD-1; red) $24 \mathrm{~h}$ after transfection with R175H, WT, K373Q, or K381/382Q acetylation mutants of p53.

To confirm these findings, which use a nonchromatinized promoter-reporter, we used ChIP analysis to examine $\mathrm{R} 175 \mathrm{H}$, WT-p53, K381Q, and K382Q binding at the endogenous Puma promoter. WT $\mathrm{p} 53$ showed greater occupancy compared with the DNA-binding deficient R175H mutant (Fig. $7 B ; p<0.001$ ). In contrast, K381Q and K382Q mutations prevented the association of p53 with the Puma promoter. Consistent with p53 binding, qRT-PCR analysis revealed a similar pattern, whereby WT p53 increased endogenous Puma expression relative to $\mathrm{R} 175 \mathrm{H}$, but K381Q and K382Q mutations prevented Puma upregulation (Fig. 7D; $p<0.05$ ). Interestingly, and supporting our previous observation that HDAC inhibition prevents p53 occupancy at the p21 promoter in neurons (Fig. $4 E$ ), these mutations also prevented p53 binding and subsequent induction of endogenous $p 21$ 

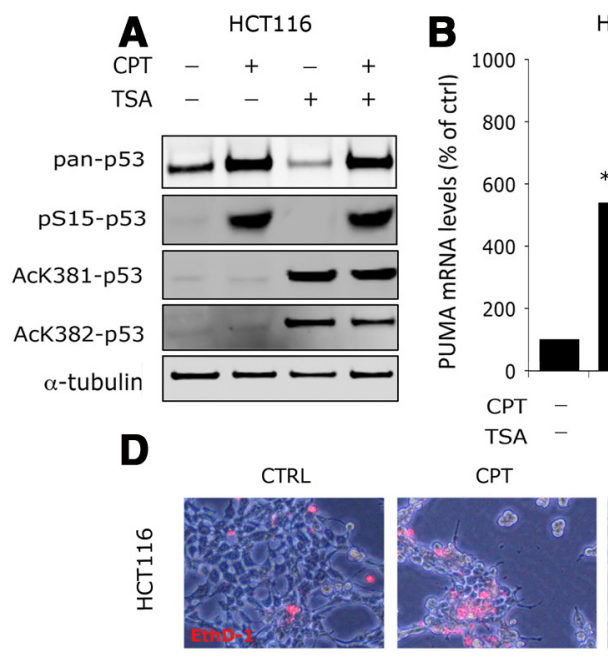

HCT116

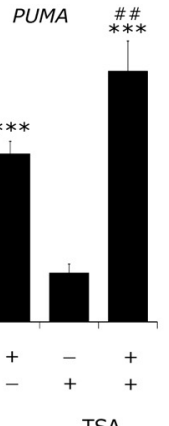

TSA

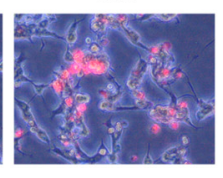

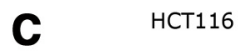

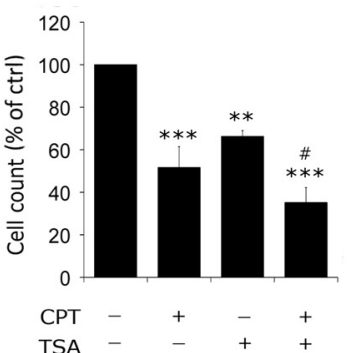

CPT TSA

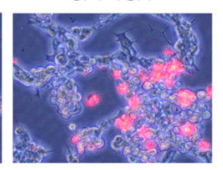

Figure 9. HDAC inhibition does not prevent PUMA induction and DNA damage-induced death in HCT116 cells. $A$, Immunoblot analysis of pan-p53, phosphorylated p53 (pS15-p53), and acetylated p53 (AcK381-p53 and AcK382-p53) in extracts from HCT116 cells treated with CPT $(20 \mu \mathrm{m})$ with or without TSA $(1.3 \mu \mathrm{m})$ for $8 \mathrm{~h}$. B, Quantitative RT-PCR of PUMA expression in HCT116 cells treated with CPT $(20 \mu \mathrm{M})$ with or without TSA $(1.3 \mu \mathrm{m})$ for $8 \mathrm{~h}$. Error bars indicate SD of mean from three independent experiments. ${ }^{* * *} p<0.001$, significant difference compared with untreated control; ${ }^{\# \#} p<0.01$, significant difference compared with (PT (one-way ANOVA followed by Bonferroni's test). C, HCT116 cell viability measured by MTT assay after treatment with CPT (20 $\mu \mathrm{M})$ with or without TSA $(1.3 \mu \mathrm{M})$. Error bars indicate SD of mean from three independent experiments. ${ }^{* *} p<0.001,{ }^{* *} p<0.01$, significant difference compared with untreated control; ${ }^{\#} p<0.05$, significant difference compared with CPT (one-way ANOVA followed by Bonferroni's test). D, HCT116 cell death assessed by ethidium homodimer staining (EthD-1; red) after treatment with CPT $(20 \mu \mathrm{m})$ with or without TSA $(1.3 \mu \mathrm{M})$.

expression, suggesting that they alter global, rather than specific, p53 transcriptional program in neurons (Fig. 7C,E).

\section{Acetylation at lysines 381 and 382 promotes $\mathrm{p} 53$ pro-apoptotic activity in cancer cells}

Our findings, thus far, demonstrate that when acetylated at lysines 381 and 382, p53 is severely defective for DNA binding, transcriptional activation, and induction of apoptosis in neurons. However, although p53 loss of function might be beneficial for the prevention of neuronal death, it increases the potential for cell transformation and cancer. This led us to investigate the consequence of acetylation at lysines 381 and 382 on the tumor suppressor function of p53 in two colorectal cancer cell lines, HCT116 and DLD-1, in which the p53-dependent induction of PUMA was initially characterized (Yu et al., 2001). We also used the immortalized murine HT22 cell line, which was derived from a primary embryonic hippocampal culture, as a model of proliferative cells of neuronal origin (Frederiksen et al., 1988).

The cell lines were transfected with wild-type, DNA-binding deficient, or acetyl-mimic mutants K373Q and K381/382Q (Fig. $8 A$ ). In all of the cell lines, promoter-reporter studies demonstrated that, similar to neurons, the overexpression of WT p53 and K373Q significantly activated the PUMA promoter compared with R175H (Fig. 8B; $p<0.001$ ). However, overexpression of $\mathrm{K} 381 / 382 \mathrm{Q}$, which did not transactivate the PUMA promoter in neurons (Fig. 7A), increased reporter expression levels in all cell lines by threefold to fourfold compared with WT p53 (Fig. $8 B ; p<0.001)$. These results suggest that acetylation at these sites, including K381/382, may also facilitate p53-induced apoptosis in HCT116, DLD-1, and HT22 cells. As expected, the overexpression of WT p53, K373Q, and K381/382Q induced death in all cell lines (Fig. 8C,D). Indeed, the overexpression of K381/382Q displayed significantly more toxicity than that of WT p53 (Fig. 8C; $p<0.01$ ). Together, these results demonstrate that in proliferat- ing cells, unlike postmitotic neurons, the acetylation of lysines 381 and 382 enhances the pro-apoptotic function of p53.

The opposing outcomes of acetylated p53 in neurons versus tumor cells are reminiscent of the neuroprotective versus anticancer properties of HDAC inhibitors. Thus, we examined the effect of HDAC inhibition on the stabilization and acetylation pattern of p53 in a cancer cell line. HCT116 cells express wild-type p53 and have been widely used as a model system to study the induction of PUMA and apoptosis by DNA damage-activated p53 (Yu et al., 2001). In agreement with our observations in neuronal cultures, treatment with CPT induced p53 stabilization and phosphorylation, which was not prevented by TSA (Fig. 9A). Conversely, TSA treatment alone did not induce stabilization or phosphorylation of p53 but increased the levels of p53 acetylated at K381 and K382 (Fig. 9A). TSA had no effect on K320 acetylation (data not shown). Since TSA treatment results in the acetylation of K381 and K382, we examined its effect on PUMA expression and survival in HCT116 cells cotreated with CPT. Quantitative RT-PCR analysis showed that, like in neurons, CPT treatment increases PUMA expression in HCT116 cells (Fig. 9B; $p<0.001$ ). However, unlike in neurons, cotreatment with TSA potentiated this induction (Fig. $9 B ; p<0.01$ ). In agreement with this, CPT-induced HCT116 cell death was not prevented, but enhanced, by cotreatment with TSA (Fig. $9 C, D ; p<0.05$ ).

\section{Discussion}

Together, neurological disease and injury represent the leading cause of disability worldwide. A number of studies suggest that p53 plays a central role in neuronal death associated with neurodegenerative disorders. Although there are clear data showing the involvement of $\mathrm{p} 53$ in the acute neuronal apoptosis observed in experimental models of epilepsy (Sakhi et al., 1996), ischemic stroke (Culmsee et al., 2003; Endo et al., 2006), and traumatic brain injury (Napieralski et al., 1999), the evidence implicating p53 in chronic neurodegeneration is mostly indirect. For instance, p53 levels have been found to be upregulated in the brain of patients suffering from Alzheimer's disease and Parkinson's disease (Esposito and Cuzzocrea, 2010), and neuronal DNA damage is one of the major features of degeneration in Huntington's disease (Jeon et al., 2012). Supporting the idea that p53 mediates neurodegeneration, deletion of $\mathrm{p} 53$ or administration of pifithrin $\alpha$, a p53 inhibitor, confers neuronal protection in various models of brain injury and disease (Culmsee et al., 2003; Endo et al., 2006; Esposito and Cuzzocrea, 2010). Interestingly, a converging line of inquiry has similarly described in vitro and in vivo neuroprotection associated with inhibition of HDAC activity. Connecting this with the idea that p 53 might be an appropriate target for neuroprotective strategies, Uo et al. (2009) have shown that HDACi prevents p53-dependent apoptosis in neurons. Using two models of p53-mediated neuronal death, DNA damage and p53 overexpression, the present data describe the mechanisms of HDACi-mediated neuroprotection. In primary 


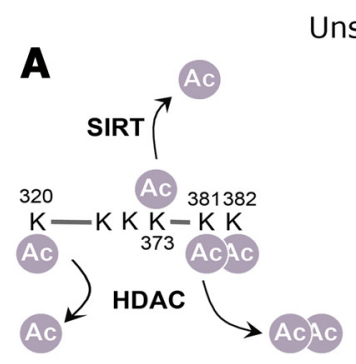

Unstressed

$$
\text { p53 C-terminus }
$$

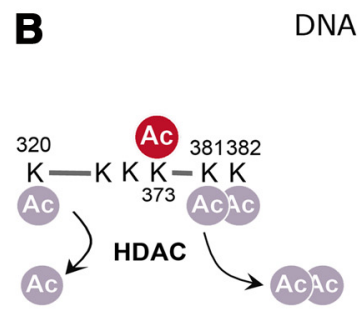

DNA damage

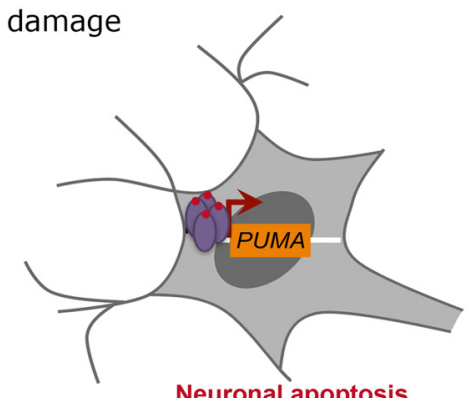

Neuronal apoptosis
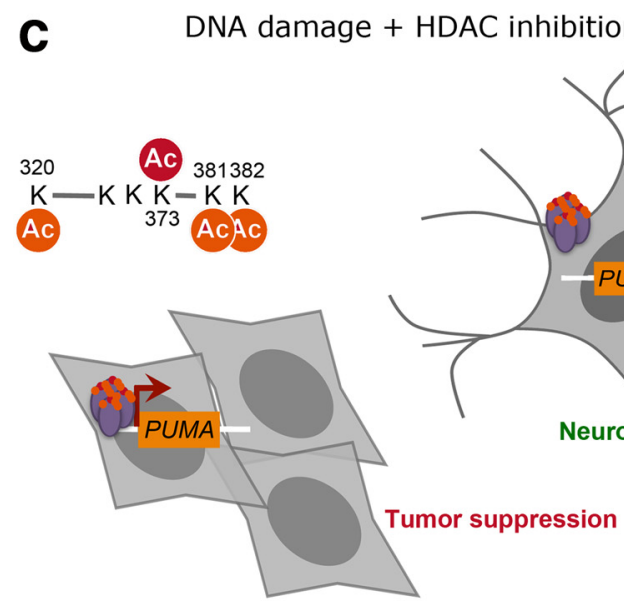

Figure 10. The acetylation pattern of $\mathrm{p} 53$ determines the fate of neurons in response to DNA damage and HDAC inhibition. $\boldsymbol{A}$, In unstressed neurons, p53 $C$ terminus is in a steady state of acetylation, resulting from the balance of the dose and activity of histone acetyltransferases, zinc-dependent HDACs, and NAD-dependent histone deacetylases (SIRTs). B, DNA damage induced by camptothecin triggers $p 53$ acetylation at lysine 373 , which, along with $p 53$ stabilization and phosphorylation at serine 15 , promotes $p 53$ binding to the pro-apoptotic PUMA promoter and leads to neuronal death. $C$, When DNA damage occurs in the presence of an HDAC inhibitor, DNA damage-induced lysine 373 acetylation occurs as in $\boldsymbol{B}$, and lysines 320, 381, and 382 are acetylated. This acetylation pattern abrogates the ability of $p 53$ to bind to the PUMA promoter and induce apoptosis in neurons but not in cancer cells.

mouse cortical cultures, which are nearly $90 \%$ neuronal, we show that global HDAC inhibition with TSA can prevent DNA damage-induced death by modifying the acetylation pattern of p53, which regulates its activity (Fig. 10).

The transcriptional potency and function of p53 are finely regulated by an integrated set of highly coordinated posttranslational modifications (Yang and Seto, 2008). It has been suggested that, in response to DNA damage, the phosphorylation of $\mathrm{N}$-terminal serines (S15, S33, S37) promotes p53 stabilization and recruits p300/CBP-associated factor and PCAF to induce p53 acetylation at C-terminal lysine residues (Lambert et al., 1998; Sakaguchi et al., 1998). In agreement with this, CPT treatment of primary cortical cultures induced p53 stabilization, S15 phosphorylation, and $\mathrm{K} 373$ acetylation (Figs. 1E, 5B). Interestingly, these events still occurred in the presence of an HDAC inhibitor, but their death-inducing effect was neutralized in neurons by the acetylation of additional lysine residues, suggesting a complex mode of regulation where precise modifications of $\mathrm{p} 53$ can counteract the effects of its stabilization and phosphorylation in a cell-type-specific fashion.

Heterologous expression of high levels of p53 has been shown to induce neuronal apoptosis (Uo et al., 2007), which can be prevented by HDAC inhibition (Fig. $6 A, B$ ). We used this model to identify the specific sites critical to the regulation of p53's activity. By overexpressing a collection of p53 acetylation mutants in neurons, we show that specific acetylation at lysine 382, and to a lesser extent at lysine 381, is sufficient for suppressing the transactivation of $\mathrm{p} 53$-dependent gene targets and promoting the survival of neuronal cultures exposed to DNA damage or deathinducing levels of p53 (Figs. $6 A-C, 10$ ). Furthermore, it had no measurable outcome on neuronal morphology (Fig. 6B). Interestingly, we show that the inhibitory effect of acetylation on p53 function is not promoter specific but seemingly disrupts the global transcriptional program of p53 by decreasing its DNAbinding affinity at both degenerate (PUMA) and highly conserved (p21) response elements (Weinberg et al., 2005; Figs. 4, 7). Remarkably, our observation that acetylation at K382 abrogates p53-dependent transcription in neurons is contrary to the current idea that acetylation at this site promotes p53's activity as a transcription factor. Indeed, acetylation of p53 at lysine 382 has been characterized to stimulate the recruitment of transcriptional coactivators, such as CBP (Mujtaba et al., 2004), TFIID (Li et al., 2007), or PC4 (Debnath et al., 2011), and enhance p53 transcriptional activity. Consistent with this, our studies in tumor cell lines show that acetylated p53, or K381/382 acetylmimic p53, displays enhanced PUMA promoter transactivation and proapoptotic activity (Figs. $8 B, C, 10$ ).

The finding that, in neurons, the same acetylation pattern of p53 at lysines 381 and 382 has opposite effects suggests that identical posttranslational modifications can have diametric outcomes in different cell types. In the context of our findings, it is possible that the acetylation status of $\mathrm{K} 381$ and $\mathrm{K} 382$, or even K382 alone, could regulate the recruitment of a neuron-specific, p53-interacting protein. For instance, apoptosis repressor with caspase recruitment domain, an endogenous inhibitor of apoptosis that is expressed primarily in terminally differentiated cells such as cardiac myocytes and neurons (Koseki et al., 1998), interacts directly with p53 to prevent tetramerization and inhibit p53dependent gene expression (Foo et al., 2007). Another possibility is that the effect acetylation has on p53 differs depending on the presence of other modifications that make up p53's posttranslational code (Yang and Seto, 2008). In this instance, such modifications may be present or absent in postmitotic versus proliferating cells. Indeed, several recent studies have demonstrated a significant degree of cross talk between p53, E2F family members, and cell-cycle checkpoint kinases, which are active during the cell cycle (Polager and Ginsberg, 2009).

The fact that the pro-survival effects of p53 acetylation at lysines 381 and 382 are limited to neurons makes it an attractive target for neuroprotective strategies. Certainly, inhibiting p53 function for the treatment of neuronal injury or disease is thought to be a double-edged sword as p53 deficiency increases spontaneous tumor rates and enhances susceptibility to carcinogens. In fact, p53 inactivation is estimated to occur in over $50 \%$ of tumors, and many strategies in cancer therapy aim at reactivating p53 (Polager and Ginsberg, 2009). Remarkably, our study reveals that a single lysine, $\mathrm{K} 382$, in the $\mathrm{C}$-terminal region of $\mathrm{p} 53$ can be 
acetylated to provide all of the neuroprotective effects of p53 inactivation in neurons, without affecting its role as a tumor suppressor in cancer cells. Moreover, our findings suggest that acetylation at this site actually potentiates the pro-apoptotic activity of p53 in cancer cells (Fig. 8C), which is consistent with the multiple studies that describe enhanced cytotoxic effects of DNAdamaging agents when combined with HDACis such as TSA or Vorinostat (Piacentini et al., 2006; Sarcar et al., 2010).

In summary, our data support the rationale for the use of small-molecule inhibitors of HDAC activity as therapeutic tools for protection in neurological injury and disease. Importantly, it provides a molecular understanding of why HDAC inhibition can promote both neuronal survival and cancer cell death; two seemingly disparate processes. Finally, it suggests that strategies aimed at enhancing p53 acetylation at lysines 381 and 382 might foster the development of compounds that would display beneficial therapeutic effects in the CNS, without compromising tumor suppression.

\section{References}

Aminova LR, Siddiq A, Ratan RR (2008) Antioxidants, HIF prolyl hydroxylase inhibitors or short interfering RNAs to BNIP3 or PUMA, can prevent prodeath effects of the transcriptional activator, HIF-1alpha, in a mouse hippocampal neuronal line. Antioxid Redox Signal 10:1989-1998. CrossRef Medline

Bakkenist CJ, Kastan MB (2003) DNA damage activates ATM through intermolecular autophosphorylation and dimer dissociation. Nature 421: 499-506. CrossRef Medline

Banin S, Moyal L, Shieh S, Taya Y, Anderson CW, Chessa L, Smorodinsky NI, Prives C, Reiss Y, Shiloh Y, Ziv Y (1998) Enhanced phosphorylation of p53 by ATM in response to DNA damage. Science 281:1674-1677. CrossRef Medline

Brooks CL, Gu W (2003) Ubiquitination, phosphorylation and acetylation: the molecular basis for p53 regulation. Curr Opin Cell Biol 15:164-171. CrossRef Medline

Chang JR, Ghafouri M, Mukerjee R, Bagashev A, Chabrashvili T, Sawaya BE (2012) Role of p53 in neurodegenerative diseases. Neurodegener Dis 9:68-80. CrossRef Medline

Choudhary C, Kumar C, Gnad F, Nielsen ML, Rehman M, Walther TC, Olsen JV, Mann M (2009) Lysine acetylation targets protein complexes and co-regulates major cellular functions. Science 325:834-840. CrossRef Medline

Culmsee C, Mattson MP (2005) p53 in neuronal apoptosis. Biochem Biophys Res Commun 331:761-777. CrossRef Medline

Culmsee C, Siewe J, Junker V, Retiounskaia M, Schwarz S, Camandola S, El-Metainy S, Behnke H, Mattson MP, Krieglstein J (2003) Reciprocal inhibition of p53 and nuclear factor-kappaB transcriptional activities determines cell survival or death in neurons. J Neurosci 23:8586-8595. Medline

Debnath S, Chatterjee S, Arif M, Kundu TK, Roy S (2011) Peptide-protein interactions suggest that acetylation of lysines 381 and 382 of p53 is important for positive coactivator 4-p53 interaction. J Biol Chem 286: 25076-25087. CrossRef Medline

Endo T, Naito K, Kume S, Nishimura Y, Kashima K, Tojo H (2006) Activities of maturation-promoting factor (MPF) and mitogen-activated protein kinase (MAPK) are not required for the global histone deacetylation observed after germinal vesicle breakdown (GVBD) in porcine oocytes. Reproduction 131:439-447. CrossRef Medline

Esposito E, Cuzzocrea S (2010) New therapeutic strategy for Parkinson's and Alzheimer's disease. Curr Med Chem 17:2764-2774. CrossRef Medline

Fischer A, Sananbenesi F, Wang X, Dobbin M, Tsai LH (2007) Recovery of learning and memory is associated with chromatin remodelling. Nature 447:178-182. CrossRef Medline

Flores ER, Tsai KY, Crowley D, Sengupta S, Yang A, McKeon F, Jacks T (2002) p63 and p73 are required for p53-dependent apoptosis in response to DNA damage. Nature 416:560-564. CrossRef Medline

Foo RS, Nam YJ, Ostreicher MJ, Metzl MD, Whelan RS, Peng CF, Ashton AW, Fu W, Mani K, Chin SF, Provenzano E, Ellis I, Figg N, Pinder S, Bennett MR, Caldas C, Kitsis RN (2007) Regulation of p53 tetrameriza- tion and nuclear export by ARC. Proc Natl Acad Sci U S A 104:2082620831. CrossRef Medline

Frederiksen K, Jat PS, Valtz N, Levy D, McKay R (1988) Immortalization of precursor cells from the mammalian CNS. Neuron 1:439-448. CrossRef Medline

Galli S, Antico Arciuch VG, Poderoso C, Converso DP, Zhou Q, Bal de Kier Joffé E, Cadenas E, Boczkowski J, Carreras MC, Poderoso JJ (2008) Tumor cell phenotype is sustained by selective MAPK oxidation in mitochondria. PLoS One 3:e2379. CrossRef Medline

Grunstein M (1997) Histone acetylation in chromatin structure and transcription. Nature 389:349-352. CrossRef Medline

Gu W, Roeder RG (1997) Activation of p53 sequence-specific DNA binding by acetylation of the p53 C-terminal domain. Cell 90:595-606. CrossRef Medline

Jabbour AM, Heraud JE, Daunt CP, Kaufmann T, Sandow J, O’Reilly LA, Callus BA, Lopez A, Strasser A, Vaux DL, Ekert PG (2009) Puma indirectly activates Bax to cause apoptosis in the absence of Bid or Bim. Cell Death Differ 16:555-563. CrossRef Medline

Jeon GS, Kim KY, Hwang YJ, Jung MK, An S, Ouchi M, Ouchi T, Kowall N, Lee J, Ryu H (2012) Deregulation of BRCA1 leads to impaired spatiotemporal dynamics of gamma-H2AX and DNA damage responses in Huntington's disease. Mol Neurobiol 45:550-563. CrossRef Medline

Kazantsev AG, Thompson LM (2008) Therapeutic application of histone deacetylase inhibitors for central nervous system disorders. Nat Rev Drug Discov 7:854-868. CrossRef Medline

Kinner A, Wu W, Staudt C, Iliakis G (2008) Gamma-H2AX in recognition and signaling of DNA double-strand breaks in the context of chromatin. Nucleic Acids Res 36:5678-5694. CrossRef Medline

Knights CD, Catania J, Di Giovanni S, Muratoglu S, Perez R, Swartzbeck A, Quong AA, Zhang X, Beerman T, Pestell RG, Avantaggiati ML (2006) Distinct p53 acetylation cassettes differentially influence gene-expression patterns and cell fate. J Cell Biol 173:533-544. CrossRef Medline

Knippschild U, Oren M, Deppert W (1996) Abrogation of wild-type p53 mediated growth-inhibition by nuclear exclusion. Oncogene 12:17551765. Medline

Koseki T, Inohara N, Chen S, Núñez G (1998) ARC, an inhibitor of apoptosis expressed in skeletal muscle and heart that interacts selectively with caspases. Proc Natl Acad Sci U S A 95:5156-5160. CrossRef Medline

Lambert PF, Kashanchi F, Radonovich MF, Shiekhattar R, Brady JN (1998) Phosphorylation of p53 serine 15 increases interaction with CBP. J Biol Chem 273:33048-33053. CrossRef Medline

Langley B, D’Annibale MA, Suh K, Ayoub I, Tolhurst A, Bastan B, Yang L, Ko B, Fisher M, Cho S, Beal MF, Ratan RR (2008) Pulse inhibition of histone deacetylases induces complete resistance to oxidative death in cortical neurons without toxicity and reveals a role for cytoplasmic p21 (waf1/ cip1) in cell cycle-independent neuroprotection. J Neurosci 28:163-176. CrossRef Medline

Langley B, Brochier C, Rivieccio MA (2009) Targeting histone deacetylases as a multifaceted approach to treat the diverse outcomes of stroke. Stroke 40:2899-2905. CrossRef Medline

Li AG, Piluso LG, Cai X, Gadd BJ, Ladurner AG, Liu X (2007) An acetylation switch in p53 mediates holo-TFIID recruitment. Mol Cell 28:408-421. CrossRef Medline

Liang SH, Hong D, Clarke MF (1998) Cooperation of a single lysine mutation and a C-terminal domain in the cytoplasmic sequestration of the p53 protein. J Biol Chem 273:19817-19821. CrossRef Medline

Morris EJ, Geller HM (1996) Induction of neuronal apoptosis by camptothecin, an inhibitor of DNA topoisomerase-I: evidence for cell cycleindependent toxicity. J Cell Biol 134:757-770. CrossRef Medline

Morrison RS, Kinoshita Y, Johnson MD, Guo W, Garden GA (2003) p53dependent cell death signaling in neurons. Neurochem Res 28:15-27. CrossRef Medline

Mujtaba S, He Y, Zeng L, Yan S, Plotnikova O, Sachchidanand, Sanchez R, Zeleznik-Le NJ, Ronai Z, Zhou MM (2004) Structural mechanism of the bromodomain of the coactivator CBP in p53 transcriptional activation. Mol Cell 13:251-263. CrossRef Medline

Napieralski JA, Raghupathi R, McIntosh TK (1999) The tumor-suppressor gene, p53, is induced in injured brain regions following experimental traumatic brain injury. Brain Res Mol Brain Res 71:78-86. CrossRef Medline

Nusinzon I, Horvath CM (2005) Histone deacetylases as transcriptional ac- 
tivators? Role reversal in inducible gene regulation. Sci STKE 2005:re11. CrossRef Medline

Olsson A, Manzl C, Strasser A, Villunger A (2007) How important are posttranslational modifications in p53 for selectivity in target-gene transcription and tumour suppression? Cell Death Differ 14:1561-1575. CrossRef Medline

Piacentini P, Donadelli M, Costanzo C, Moore PS, Palmieri M, Scarpa A (2006) Trichostatin A enhances the response of chemotherapeutic agents in inhibiting pancreatic cancer cell proliferation. Virchows Arch 448:797804. CrossRef Medline

Polager S, Ginsberg D (2009) p53 and E2f: partners in life and death. Nat Rev Cancer 9:738-748. CrossRef Medline

Riley T, Sontag E, Chen P, Levine A (2008) Transcriptional control of human p53-regulated genes. Nat Rev Mol Cell Biol 9:402-412. CrossRef Medline

Rivieccio MA, Brochier C, Willis DE, Walker BA, D’Annibale MA, McLaughlin K, Siddiq A, Kozikowski AP, Jaffrey SR, Twiss JL, Ratan RR, Langley B (2009) HDAC6 is a target for protection and regeneration following injury in the nervous system. Proc Natl Acad Sci U S A 106:19599-19604. CrossRef Medline

Rouaux C, Loeffler JP, Boutillier AL (2004) Targeting CREB-binding protein (CBP) loss of function as a therapeutic strategy in neurological disorders. Biochem Pharmacol 68:1157-1164. CrossRef Medline

Ryan JJ, Clarke MF (1994) Alteration of p53 conformation and induction of apoptosis in a murine erythroleukemia cell line by dimethylsulfoxide. Leuk Res 18:617-621. CrossRef Medline

Sakaguchi K, Herrera JE, Saito S, Miki T, Bustin M, Vassilev A, Anderson CW, Appella E (1998) DNA damage activates p53 through a phosphorylationacetylation cascade. Genes Dev 12:2831-2841. CrossRef Medline

Sakhi S, Sun N, Wing LL, Mehta P, Schreiber SS (1996) Nuclear accumulation of $\mathrm{p} 53$ protein following kainic acid-induced seizures. Neuroreport 7:493-496. CrossRef Medline

Sarcar B, Kahali S, Chinnaiyan P (2010) Vorinostat enhances the cytotoxic effects of the topoisomerase I inhibitor SN38 in glioblastoma cell lines. J Neurooncol 99:201-207. CrossRef Medline
Sleiman SF, Langley BC, Basso M, Berlin J, Xia L, Payappilly JB, Kharel MK, Guo H, Marsh JL, Thompson LM, Mahishi L, Ahuja P, MacLellan WR, Geschwind DH, Coppola G, Rohr J, Ratan RR (2011) Mithramycin is a gene-selective Sp1 inhibitor that identifies a biological intersection between cancer and neurodegeneration. J Neurosci 31:6858-6870. CrossRef Medline

Smyth GK, Michaud J, Scott HS (2005) Use of within-array replicate spots for assessing differential expression in microarray experiments. Bioinformatics 21:2067-2075. CrossRef Medline

Uo T, Kinoshita Y, Morrison RS (2007) Apoptotic actions of p53 require transcriptional activation of PUMA and do not involve a direct mitochondrial/cytoplasmic site of action in postnatal cortical neurons. J Neurosci 27:12198-12210. CrossRef Medline

Uo T, Veenstra TD, Morrison RS (2009) Histone deacetylase inhibitors prevent p53-dependent and p53-independent Bax-mediated neuronal apoptosis through two distinct mechanisms. J Neurosci 29:2824-2832. CrossRef Medline

Weinberg RL, Veprintsev DB, Bycroft M, Fersht AR (2005) Comparative binding of $\mathrm{p} 53$ to its promoter and DNA recognition elements. J Mol Biol 348:589-596. CrossRef Medline

Yamaguchi H, Woods NT, Piluso LG, Lee HH, Chen J, Bhalla KN, Monteiro A, Liu X, Hung MC, Wang HG (2009) p53 acetylation is crucial for its transcription-independent proapoptotic functions. J Biol Chem 284: 11171-11183. CrossRef Medline

Yang XJ, Seto E (2008) Lysine acetylation: codified crosstalk with other posttranslational modifications. Mol Cell 31:449-461. CrossRef Medline

Yu J, Zhang L, Hwang PM, Kinzler KW, Vogelstein B (2001) PUMA induces the rapid apoptosis of colorectal cancer cells. Mol Cell 7:673-682. CrossRef Medline

Zhao Y, Lu S, Wu L, Chai G, Wang H, Chen Y, Sun J, Yu Y, Zhou W, Zheng Q, Wu M, Otterson GA, Zhu WG (2006) Acetylation of p53 at lysine 373/ 382 by the histone deacetylase inhibitor depsipeptide induces expression of p21(Waf1/Cip1). Mol Cell Biol 26:2782-2790. CrossRef Medline 